\title{
Drivers behind the summer 2010 wave train leading to Russian heatwave and Pakistan flooding
}

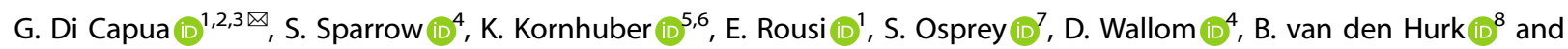 \\ D. Coumou iD $1,2,9$
}

Summer 2010 saw two simultaneous extremes linked by an atmospheric wave train: a record-breaking heatwave in Russia and severe floods in Pakistan. Here, we study this wave event using a large ensemble climate model experiment. First, we show that the circulation in 2010 reflected a recurrent wave train connecting the heatwave and flooding events. Second, we show that the occurrence of the wave train is favored by three drivers: (1) 2010 sea surface temperature anomalies increase the probability of this wave train by a factor 2-to-4 relative to the model's climatology, (2) early-summer soil moisture deficit in Russia not only increases the probability of local heatwaves, but also enhances rainfall extremes over Pakistan by forcing an atmospheric wave response, and (3) high-latitude land warming favors wave-train occurrence and therefore rainfall and heat extremes. These findings highlight the complexity and synergistic interactions between different drivers, reconciling some seemingly contradictory results from previous studies.

npj Climate and Atmospheric Science (2021)4:55; https://doi.org/10.1038/s41612-021-00211-9

\section{INTRODUCTION}

In summer 2010, a strongly meandering jet stream connected two simultaneous extreme weather events, the Russian heatwave, and the Pakistan flood, leading to severe societal impacts. By the end of July, beginning of August 2010, a series of heavy rainfall outpours hit Pakistan and the western Himalayan foothills region, causing the flooding of one-fifth of the country, severe damage to infrastructure, and taking the lives of 1700 people $^{1,2}$. Simultaneously, western Russia was hit by a severe heatwave with anomalously warm temperatures from the end of June until midAugust ${ }^{1}$. The heatwave was accompanied by drought conditions and forest fires and may have caused the death of $\sim 15,000-55,000$ people $\mathrm{e}^{1,3}$. These events were characterized by a semi-permanent blocking anticyclone accompanied by air subsidence, adiabatic warming, reduced cloudiness, and soil drying ${ }^{1,4-7}$. Below normal soil moisture limits evapotranspiration, reducing cloudiness and further exacerbating land warming ${ }^{1,5}$. Over Pakistan, a combination of a mid-tropospheric trough bringing relatively dry and cold air from the mid-latitudes, high sea surface temperatures (SST) over the Arabian Sea, and La Niña conditions in the tropical Pacific, allows the advection of moisture into the region ${ }^{1,8}$. This situation led to 3 weeks of intense rainfall over the region, with rainfall anomalies $300 \%$ higher than the climatology for the same period $^{1,2,7}$. These two extreme events were connected by an unusually wavy jet stream ${ }^{1}$. Such wave trains can have a strong impact on surface weather conditions and weather extremes, and in particular on heatwaves, with possible consequences for simultaneous crop failures in the northern mid-latitudes?

Thermodynamic warming of the atmosphere intensifies heatwaves and rainfall extremes ${ }^{10,11}$. Extreme rainfall events have increased in recent decades and model simulations project further increases due to thermodynamics, although uncertainties are larger for rainfall than for temperature changes ${ }^{11-15}$. The frequency of heat extremes over Europe has increased in recent decades at a pace that cannot be explained by atmospheric thermodynamics alone ${ }^{16-18}$. The effects of global warming on dynamics, including summer wave trains and blocking, are not well understood ${ }^{9,19-24}$. Blockings and atmospheric Rossby waves could contribute to changes in the probability and persistence of extreme warm events in summer $21,25,26$. Some studies suggest that the frequency of occurrence of the mid-latitude wave pattern that characterized summer 2010 and led to the Russian heatwave has greatly increased since $1990^{21}$, though results are sensitive to the metric used and the analyzed region ${ }^{27,28}$.

SST, especially in the tropics, have a strong influence in shaping atmospheric waves in the North Atlantic/European ${ }^{29-31}$ and North American sector in boreal summer ${ }^{32}$. SST and tropical convection can act as a source of circumglobal wave trains, thus influencing the mid-latitude circulation ${ }^{29,33-36}$. In summer 2010, La Niña-like SST anomalies co-occurred with a warmer than the usual Indian Ocean and a negative Indian Ocean Dipole phase ${ }^{37}$. Model simulations of the 2010 Pakistan flood event show that these SST anomalies are instrumental in causing the circulation anomalies that led to the anomalous rainfall over Pakistan and northern India ${ }^{8}$. Moreover, the combined dynamical and thermodynamic response to anthropogenic-induced trends in SST patterns, shown in atmospheric models, increases the probability of occurrence of the Russian heatwave ${ }^{38}$.

Recent work suggests that high-latitude land warming can also affect the development and persistence of atmospheric wave patterns in boreal summer. Quasi-resonant amplification (QRA) refers to the amplification of synoptic-scale quasi-stationary free waves due to the presence of a mid-latitude waveguide in the zonal wind field ${ }^{22}$. QRA has been linked to the occurrence of

\footnotetext{
'Potsdam Institute for Climate Impact Research (PIK), Leibniz Association, Potsdam, Germany. ${ }^{2}$ Institute for Environmental Studies (IVM), Vrije Universiteit (VU) Amsterdam, Amsterdam, Netherlands. ${ }^{3}$ Department of Water, Environment, Construction and Safety, Magdeburg-Stendal Technical University, Magdeburg, Germany. ${ }^{4}$ Oxford e-Research Centre, University of Oxford, Oxford, UK. ${ }^{5}$ Earth Institute, Columbia University, New York, USA. ${ }^{6}$ Lamont-Doherty Earth observatory, Columbia University, New York, USA. ${ }^{7}$ Atmospheric Physics Clarendon Laboratory, University of Oxford, Oxford, UK. ${ }^{8}$ Deltares, Delft, Netherlands. ${ }^{9}$ Royal Netherlands Meteorological Institute (KNMI), De Bilt, Netherlands. ${ }^{凶}$ email: dicapua@pik-potsdam.de
} 
amplified planetary waves and some recent heatwaves in the midlatitudes, including the Russian heatwave in $2010^{39}$. Anthropogenic climate change and in particular enhanced warming over high-latitude land areas might alter the characteristics of these waves by two possible mechanisms: (i) weakening of jet stream and storm tracks, which could, in turn, make wave trains more persistent ${ }^{19,25}$; and (ii) favoring double jet states characterized by a confined sub-tropical jet that acts as an efficient waveguide ${ }^{39,40}$. These mechanisms may create more favorable conditions for the formation of waveguides and amplified wave patterns and thus for extreme weather ${ }^{19,40}$.

Soil moisture anomalies can act as a source of Rossby waves and thus represent another surface forcing that can impact largescale dynamics and induce or exacerbate heatwaves in the midlatitudes ${ }^{41}$. In northern mid-latitudes, model experiments have shown that dry soils can induce terrestrial heating anomalies which in turn can lead to a stronger wave response ${ }^{41-43}$. Soil moisture changes related to global warming could act to exacerbate the impact of heatwave events ${ }^{44}$. Summer soil moisture in extratropical regions is projected to decrease with climate change and such regional changes can substantially affect the climate in both hemispheres, with stronger and more robust impacts on surface temperatures than rainfall ${ }^{45,46}$. Future changes in soil moisture patterns may further exacerbate extreme events characterized by atmospheric circulation patterns similar to those observed in $2010^{47,48}$.

Here, we study the influence of SST patterns (together with global warming), high-latitude land warming, and early summer soil moisture conditions by quantifying their respective contribution to the 2010 Russian and Pakistan extremes. To do so, we use a very large ensemble of general circulation model simulations forced with observed SST anomalies and radiative forcings provided by the weather@home/climateprediction.com project. We use the global climate model of weather@home and a oneway nested $50 \mathrm{~km}$ regional climate model covering the South Asia region (region boundaries denoted in Supplementary Fig. 1). The regional model domain is much larger than the study area ensuring that any boundary effects in the region of interest are minimal. We quantify the relative contribution of these mechanisms to the probability of occurrence of the joint events, reconciling earlier findings on these interactions.

\section{RESULTS}

\section{The 2010 Russian and Pakistan extremes}

A circumglobal wave, visible in observed meridional winds and geopotential height data (Fig. 1e, f), connects the extreme temperature in Russia (Fig. 1a) with rainfall anomalies in Pakistan (Fig. 1c). Figure $1 \mathrm{~b}$ shows the probability density function (PDF) of standardized surface atmospheric temperature (SAT) anomalies over WRussia based on the observed 1987-2015 climatology (consistent with the available weather@home climatology). The observed mean value for this region is $293.1 \mathrm{~K}\left(=20.1^{\circ} \mathrm{C}\right)$, with an interannual standard deviation (s.d.) of $1.7 \mathrm{~K}$. Figure $1 \mathrm{~d}$ shows the PDF of standardized anomalies of observed Pakistan Rainfall for the 1987-2015 period. The mean value is $2.7 \mathrm{~mm} /$ day, with an s.d. of $0.9 \mathrm{~mm} /$ day. Both WRussia SAT and Pakistan Rainfall indices have an outlier in 2010, with both extremes exceeding 3 s.d. above the mean.

Figure 2 shows a schematic of the model experiment setup together with their corresponding labels. The 2010 large ensemble provided by weather@home is labeled as Glob2010 for the global model and as Reg2010 for the regional model. The corresponding 1987-2015 model climatologies are labeled as GlobClim and RegClim, respectively. See the "Methods" section for further information on the model experiment setup and the definitions of indices.
Our model experiment shows the relative contribution of drivers to the extreme SAT and Rainfall of summer 2010 by conditioning on different potential drivers (Fig. 3). In GlobClim, concurrent events occur twice as frequently as expected for independent variables, supporting the significance of the role of an atmospheric wave train for their concurrent occurrence. In both Glob2010 and Reg2010 these events have clearly larger probability to occur, both individually and in concurrent mode. In 2010, exceedance probabilities increase approximately by a factor of 2 for WRussia SAT index and by a factor 4 for both the Pakistan Rainfall index and the concurrent event. Conditioning on drier soils (Glob2010 | soils and Reg2010|soilM) over western Russia in June and high-latitude land warming (Glob2010|T65N and Reg2010|T65N) in July-August, further enhances these probabilities by a factor of $\sim 2.5$ for WRussia SAT index to a factor of $\sim 5$ for the Pakistan Rainfall index.

\section{A recurrent wave connecting the extremes}

Figure 4 shows the ensemble mean composites for SAT over Eurasia (Fig. 4a), Z300 (Fig. 4g), and V300 (Fig. 4h) from Glob2010, and for rainfall over the Indian subcontinent from both Glob2010 and Reg2010 (Fig. 4c and e, respectively). A pronounced atmospheric wave-5 pattern and associated warm anomalies in Russia (shifted eastward as compared to the observed anomalies, black box in Figs. 1a and 4a), and increased rainfall over Pakistan up to $\sim 3 \mathrm{~mm} /$ day higher than the climatology are shown. Rainfall from Reg2010 (Fig. 4e) shows the same pattern and magnitude as for Glob2010 (Fig. 4c), though with a more detailed small-scale structure close to the Himalayan Mountain range. In all three cases, the 2010 PDFs are shifted towards higher values compared to the climatological PDF (Fig. 4b, d, f). The PDFs are estimated from 649 temperature values for both Glob2010 and Reg2010, and 4930 (2871) precipitation values for GlobClim (RegClim), i.e. one value for each member and/or year. Temperature and precipitation data are standardized based on the mean and standard deviations of GlobClim and RegClim, respectively. GlobClim has an average SAT of $296.4 \mathrm{~K}$, i.e. $3.3 \mathrm{~K}$ above the observed climatological mean for WRussia in the period 25.07-08.08, and an s.d. = $2.4 \mathrm{~K}$. GlobClim (RegClim) has a mean rainfall value of $3.50 \mathrm{~mm} /$ day $(3.36 \mathrm{~mm} /$ day $)$ and an s.d. of $0.59 \mathrm{~mm} /$ day $(0.53 \mathrm{~mm} /$ day $)$. To account for the model bias with respect to observations, we standardize the model's output by subtracting the mean and dividing by standard deviation. The observed SST pattern used as boundary conditions for the 2010 model experiments can be seen in Supplementary Fig. 2.

The number of extreme events for the WRussia SAT index increases from $10 \%$ (i.e. 90th percentile) to $\sim 17 \%$ in Glob2010, while for the Pakistan Rainfall index it increases from $10 \%$ to $~ 34 \%$ in Glob2010 (43\% in Reg2010), i.e. by about a factor 3-4. The percentage of ensemble members exceeding the 2010 threshold in the climatology is shown together with the percentage of ensemble members exceeding the 2010 threshold in the Glob2010 (or Reg2010) ensemble (see Fig. 4b, $d, f$ ). While the WRussia SAT index never reaches the observed (standardized) 2010 threshold, the Pakistan Rainfall indices jump from a $0.2 \%$ of occurrence in the climatology to a $0.8 \%$ and $1.4 \%$ in Glob2010 and Reg2010, respectively. Thus, there is a 4-to-7-fold increase in extreme rainfall events in this region linked to 2010 forcing conditions. Thus, the combination of 2010 SST patterns and radiative forcings strongly influences the appearance of these two interconnected extremes. All pairs of PDFs shown in Fig. 4b, d, and $f$ are significantly different from each other using $a$ Kolmogorov-Smirnov test and a significance level of $a=0.05$ (see Supplementary Table 1).

The WRussia SAT 2010 event was so extreme that neither the climatology of the model nor the 2010 ensemble can reproduce values exceeding its threshold (Fig. 4b). This implies that the occurrence probability for such extreme temperatures in the $\mathrm{W} @ \mathrm{H}$ 
Pakistan flood - Russian heatwave, 25.07-08.08 2010
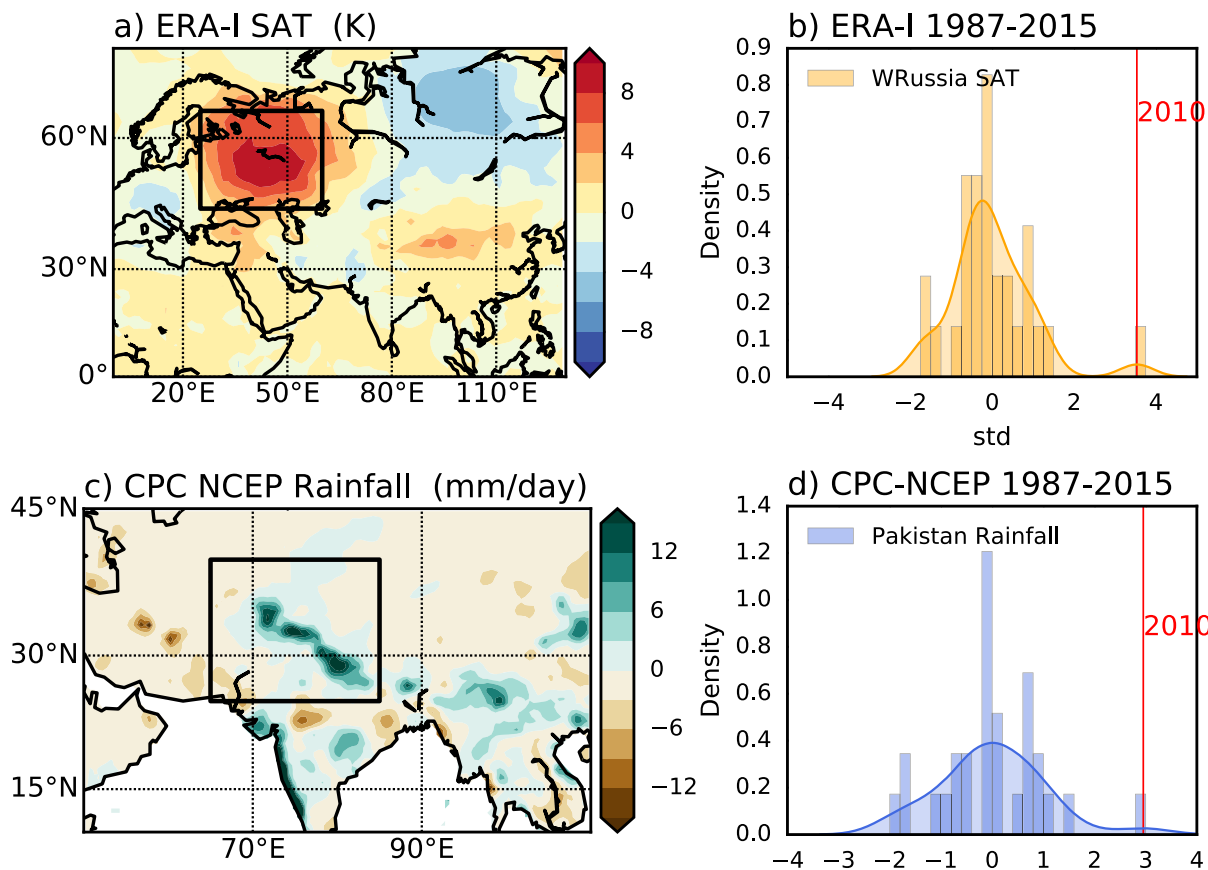

d) CPC-NCEP 1987-2015

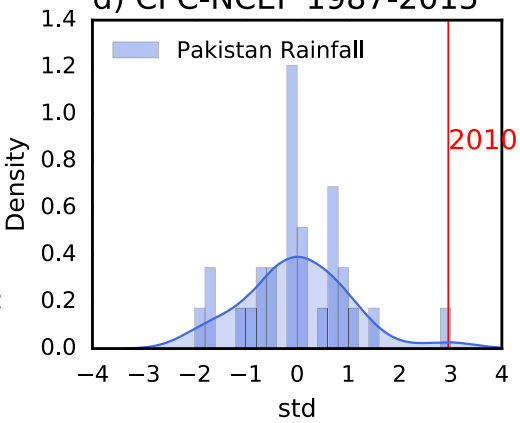

e) ERA-I Z300 (m)
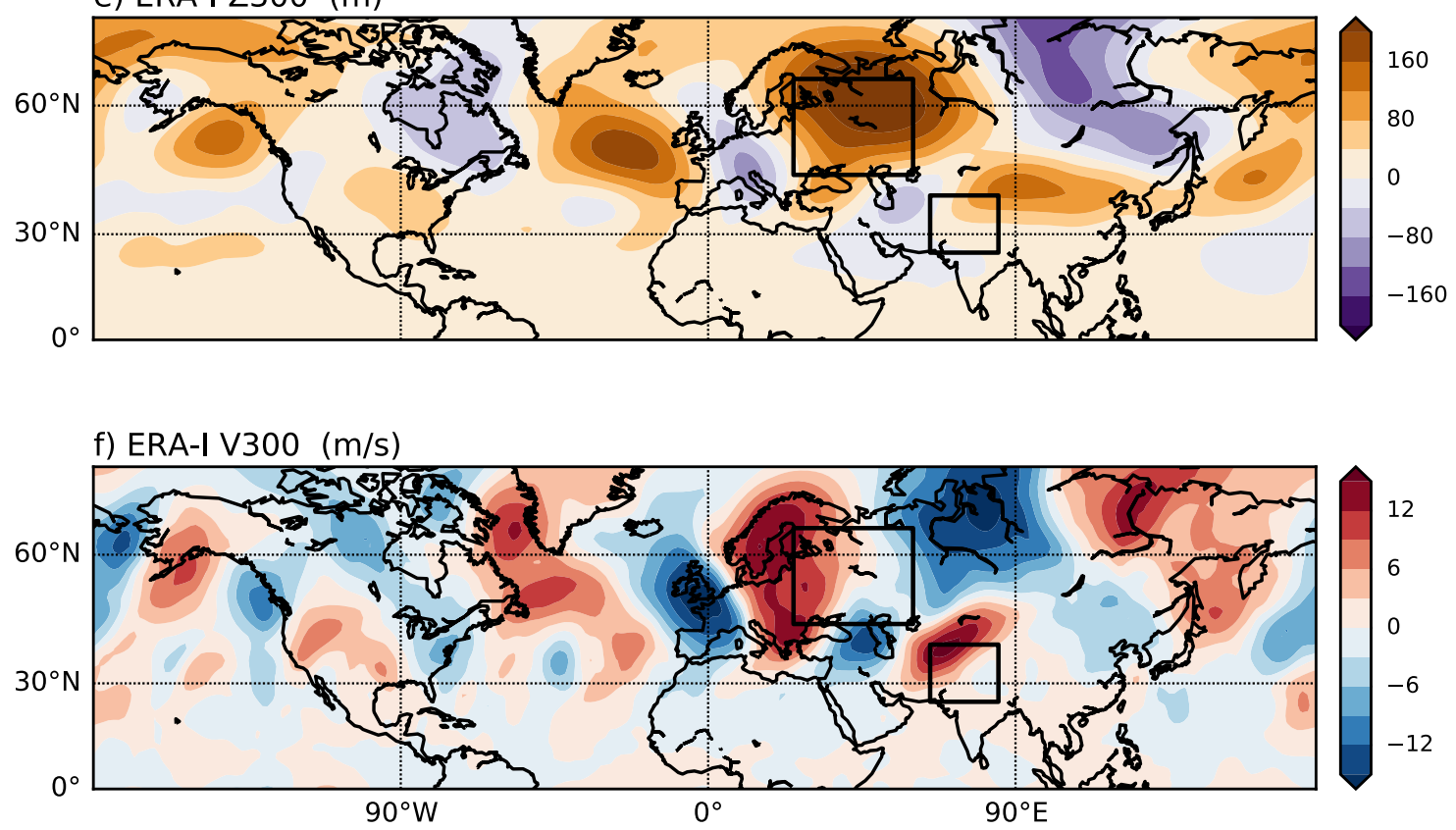

Fig. 1 Observational temperature, precipitation, and circulation anomalies in summer 2010. Panel a: ERA-I surface air temperature at $2 \mathrm{~m}$ (SAT) anomalies over Eurasia. Panel b: 1987-2015 probability density function for SAT index averaged over the western Russia (WRussia) region, highlighted by a black box in Panel a. Panel c: Same as for panel a but for CPC/NCEP Rainfall anomalies over South Asia. Panel d: probability density function for Rainfall index averaged over the Pakistan region, highlighted by a black box in Panel c. Panel e: Same as for panel a but for ERA-I geopotential height at $300 \mathrm{hPa}$ (Z300) anomalies. Panel f: Same as for panel a but for ERA-I meridional wind component at $300 \mathrm{hPa}$ (V300) anomalies. In both panels $\mathbf{b}$ and $\mathbf{d}$ vertical red lines highlight 2010 values for SAT and Rainfall respectively. All anomalies are calculated for the period 25.07-08.08.2010 based on the 1987-2015 climatology of 25.07-08.08. The smoothing of the curve is done using a Gaussian kernel to produce continuous density estimates.

2010 ensemble is lower than $0.2 \%$ (or a one in the 500 -year event) indicating that even under present-day GHG forcing the event was extremely rare. These estimated return times are higher than Otto et al. $(2012)^{49}$ - who reported a return-time of 33 years in the 2000 s climate. However, their definition was based on the monthly mean July temperatures whereas we focus on a shorter period of 2 weeks coinciding with the most extreme temperature anomalies ${ }^{5}$ and rainfall extremes over Pakistan. 
(a) Observations

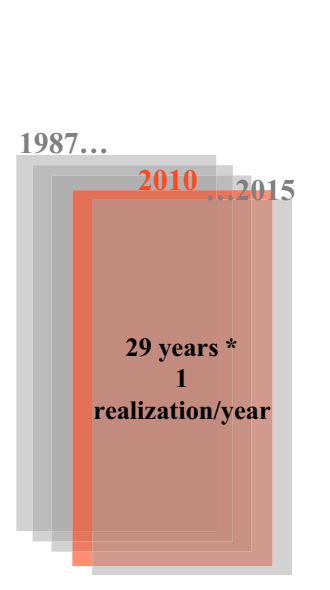

- SAT

- Z300

- V300

- Rainfall

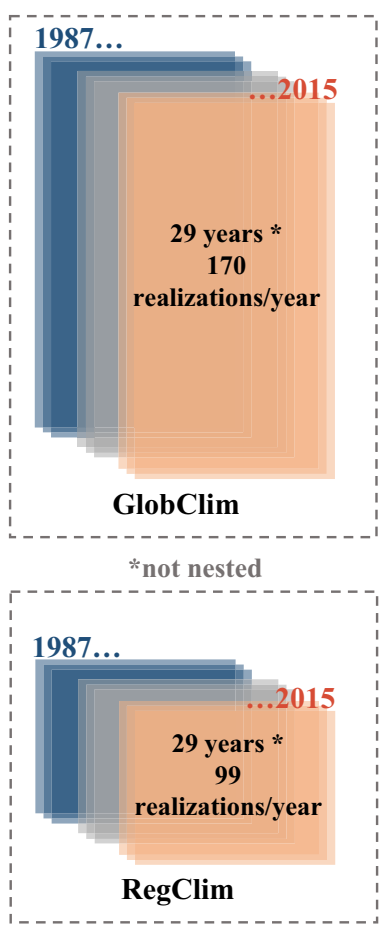

(b) Weather@home

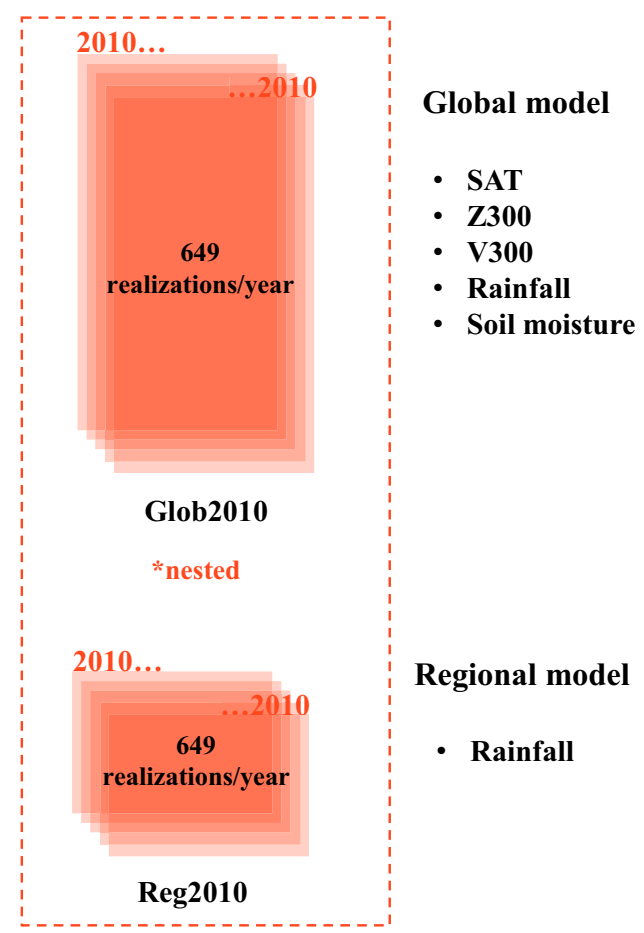

Fig. 2 Schematic of model experiment. Panel a: Observations. Panel b: weather@home climatology for the global model (GlobClim) and for the regional model (RegClim) (gray dashed box) and 2010 large-ensemble for the global model (Glob2010) and for the regional model (Reg2010) (red dashed box). While Reg2010 is directly nested on Glob2020, RegClim is nested on a different set of global simulations than those contained in GlobClim. See Supplementary Discussion 1 for further information.

A circumglobal wave with a wavenumber 5 appears both in geopotential height (Z300, Fig. 4g) and meridional winds (V300, Fig. 4h) in the 2010 ensemble mean, showing generally higher than usual Z300 values when compared to the climatology of the model (see also Supplementary Discussion 2 and Supplementary Fig. 3), in agreement with higher than usual SAT shown in Fig. 4a. V300 anomalies follow the ridges shown in the Z300 plot. This wave pattern shows similarities to the observed 2010 wave train (Fig. 1e, f), especially over the Atlantic-European sector. However, observed SAT anomalies are about a factor 4 stronger in observations (Fig. 1a) compared to the 2010 ensemble mean (Fig. 4a) and shifted more to the west. This difference can be explained by the fact that the ensemble mean contains 649 possible realizations of 2010 (compared to one in real-life observations). This shows the importance of 2010-SST patterns in forcing the circumglobal wave train behind the heat- and rainfall extremes. However, 2010 anomalies cannot be deterministically explained only by the 2010 SST field and radiative forcings. Next to these forcings, other effects from soil moisture variability, land-atmosphere dynamics, and model bias are likely to play a role and may determine the shift in the phase position of the atmospheric wave pattern.

Figure 5 shows that a recurrent circumglobal wave pattern connects the Russia and Pakistan events, and therefore extremes in these regions are correlated ${ }^{50}$. Here, we define a wave pattern as recurrent when its spatial (wave number and phase position) and temporal (duration) characteristics are similar among pronounced wave-events in different ensemble members, similarly to the definition in Kornhuber et al. $(2019)^{50}$. Note that anomalies for the sub-selections of Glob2010 and Reg2010 are compared to the ensemble mean of Glob2010 and Reg2010, and not compared to GlobClim or RegClim. We do this because we are interested in how different (pre)conditions within 2010 affect the occurrence of extremes, beyond what's driven by SSTs (as shown in Fig. 4). Figure $5 b$ shows how the percentage of concurrent events (see the "Methods" section for the definition) changes between the climatology of the model and the 2010 run, with a $\sim 4$-fold increase $(\sim 8-9 \%)$ of 2010 concurrent events with respect to the climatology of the model $(\sim 2 \%)$. It is important to notice that, already in GlobClim, this percentage is $\sim 2 \%$, thus twice as large as expected for independent extremes $(0.1 \times 0.1=1 \%)$. Note that we can calculate this value only for the global model ensemble, as the regional rainfall data for the climatological run come from a different ensemble of model simulations (batch) of initial conditions (see Supplementary Discussion 1 for further information). For concurrent events selected in Glob2010 and Reg2010 ensembles, this percentage jumps to 8\% and $\sim 9 \%$, respectively, showing how exceptional 2010 was. Composites of concurrent events (Fig. 5a, c-f) show patterns largely resembling those seen in the observations (Fig. 1) for the Atlantic-Eurasian sector. The same composites for SAT, Z300, and V300 but obtained with Rainfall from Glob2010 (Fig. 5c) are shown in the Supplementary Information (Supplementary Fig. 4). SAT over western Russia shows values up to $\sim 4 \mathrm{~K}$ higher than the 2010 ensemble mean (Fig. 5a), while rainfall over Pakistan shows values between 2 and $4 \mathrm{~mm} /$ day higher than the 2010 ensemble mean (Fig. 5c). In Z300 and V300 fields, a pronounced wave over the Eurasian continent is shown, with positive anomalies for Z300 centered over western Russia and strongest V300 anomalies, showing southerly winds to the west and northerly winds to the east of this positive Z300 anomaly (Fig. 5e, f).

\section{The effect of high-latitude land warming and dry soils}

By conditioning on high-latitude land warming in the 2010 ensemble (Glob2010|T65N or Reg2010|T65N, see the "Methods" 

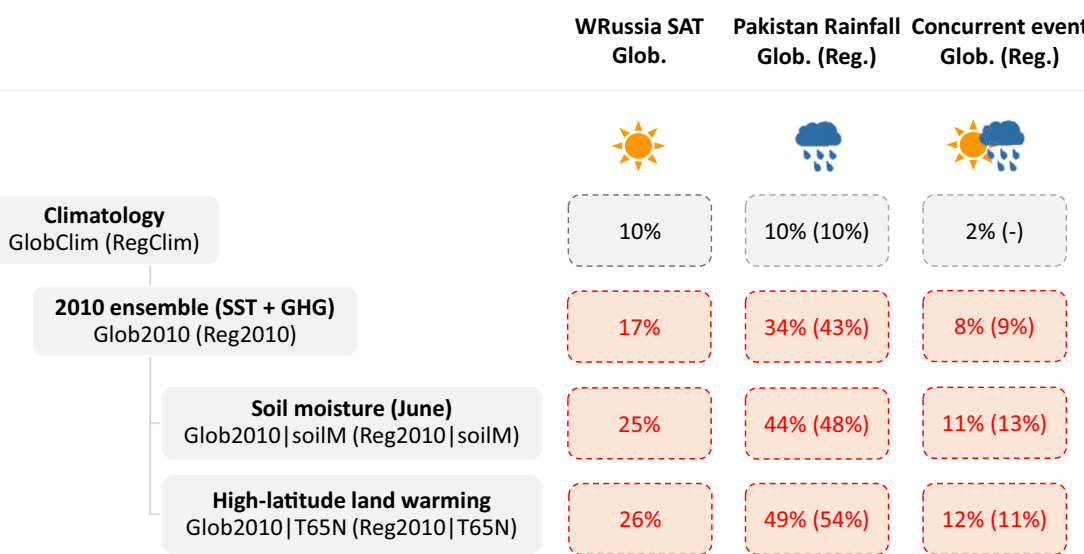

Glob. (Reg.)

Glob2010|T65N (Reg2010|T65N)
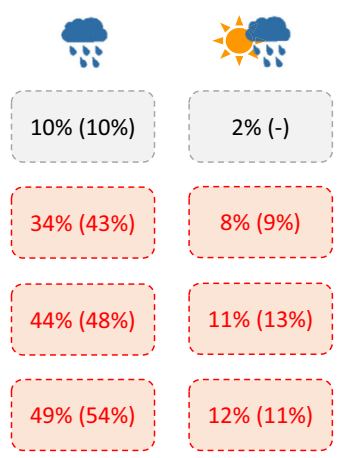

Fig. 3 Schematic of $\mathbf{2 0 1 0}$ extremes probabilities derived from W@H. First row: the probability of exceeding the 90th percentile threshold for WRussia SAT and Pakistan Rainfall Indices and probability of exceeding both the 90th thresholds for both WRussia SAT and Pakistan Rainfall contemporaneously in GlobClim. $10 \%$ probabilities in the climatology row of the WRussia SAT and Pakistan Rainfall columns are true by construction. Pakistan Rainfall is available for both global and regional model runs but WRussia SAT is available only for global simulations as the Regional model is centered over South Asia. Concurrent events probability cannot be carried out for RegClim since this ensemble of simulation is not nested on the analyzed GlobClim ensemble. Second row: Same as the first row but for Glob2010 (SAT and Rainfall) and Reg2010 (Rainfall). Third row: Same as the first row but for a sub-selection of ensemble members in Glob2010 (SAT and Rainfall) and Reg2010 (Rainfall) showing dry soil conditions over western Russia in June. Fourth row: Same as the first row but for a sub-selection of ensemble members in Glob2010 (SAT and Rainfall) and Reg2010 (Rainfall) showing high-latitude land warming signal in the 24.07-08.08 period.

section), the probability of occurrence of both extreme events further increases (Fig. 6). As for Fig. 5, anomalies are deviations from the Glob2010 (or Reg2010) ensemble. While we select for zonal-mean land warming that peaks around $65^{\circ} \mathrm{N}$, two main warming anomalies appear south of that latitude $\left(\sim 50^{\circ} \mathrm{N}\right)$, i.e. over central Canada and from Eastern Europe to central Asia (Fig. 6a). WRussia SAT extremes increase from 17\% for Glob2010 to 26\% in Glob2010 | T65N, thus with an absolute increase of $~ 10 \%$ (Fig. 6c). Pakistan rainfall shows an increase of the percentage of extreme wet events from $\sim 43 \%$ in in Reg2010 to $54 \%$ in Reg2010|T65N (Fig. 6e). The corresponding composites of SAT for Glob2010|T65N (exceeding the 90th percentile) and also exceeding the 90th WRussia SAT index (GlobClim) percentile (Fig. 6b) and of Rainfall for Reg2010|T65N (exceeding the 90th percentile) and also exceeding the 90th Pakistan Rainfall index (RegClim) percentile (Fig. 6d) show positive SAT anomalies over western Russia paired with enhanced rainfall over the Himalayan foothills and the Indus basin. The PDF pairs shown in Fig. $6 \mathrm{c}$ and e are significantly different using the Kolmogorov-Smirnov test (see Supplementary Table 1).

Drier than usual early season (June) soil moisture conditions increase the probability of both 2010 extremes (Fig. 7). Figure 7a shows composites of June soil moisture for Glob2010|soilM compared to the Glob2010 ensemble mean. Composites for SAT (Fig. 7b) and Pakistan rainfall (Fig. 7d) from ensemble members with drier soils show a higher percentage of extremes (Fig. 7c, e). WRussia SAT extremes go from $\sim 17 \%$ of Glob2010 to $\sim 25 \%$ in Glob2010|soilM. The percentage of Pakistan Rainfall extremes increases from $43 \%$ in Reg2010 to 48\% in Reg2010|soilM. This shows that dry soils in western Russia increase the probability of extreme heat over WRussia (i.e. its endemic region) but also influence extreme rainfall in Pakistan by strengthening the connecting wave train (see Supplementary Fig. 5). The effect on extreme rainfall in Pakistan is similar for Glob2010 (Supplementary Fig. 6) though the increase in the far tail is somewhat smaller probably due to the lower resolution. The higher resolution of the regional model improves topographic representation and convective activity and is, therefore, better suited for very extreme rainfall events. The PDF pairs are shown in Fig. 7c and e are significantly different using the Kolmogorov-Smirnov test (see Supplementary Table 1).
Both for Figs. 6 and 7, we also produce similar plots (i) selecting only soilM or T65N events without double-selecting also on WRussia SAT and Pakistan Rainfall extremes (Supplementary Figs. 7 and 8), (ii) using Glob2010 rainfall instead of Reg2010 rainfall (Supplementary Figs. 6 and 9) and (iii) showing the corresponding composites for Z300 and V300 (Supplementary Figs. 5 and 10). A detailed description of these figures is found in Supplementary Discussion 3.

Finally, we analyze how the concurrent extreme is influenced by either dry soils in June or contemporaneous high-latitude land warming. Figure 8 shows the PDFs for the 2010 events that are characterized by high-latitude land warming signals or dry June soil moisture conditions. The probability of concurrent extremes (shown in the upper-right gray-shaded corner) greatly increases in the 2010 ensemble to $8.3 \%$, or about a 5 -fold increase. When we condition on (contemporaneous) high-latitude land warming or dry soil moisture conditions (in June), the percentage of concurrent events increases to $12.3 \%$ and $10.9 \%$, respectively, in Glob2010. This thus represents a $30-50 \%$ increase if compared to the full 2010 ensemble. Similar results are obtained for Reg2010 (Supplementary Fig. 11).

\section{DISCUSSION}

Between late July and early August, an atmospheric wave train connected the western Russia heatwave with the Pakistan flood. Using a very large model ensemble, we show that this wave can be reproduced by the weather@home model. Already in the model's climatology, this recurrent wave connects the two extremes, making the probability of having a concurrent extreme (i.e. surface temperatures over western Russia and rainfall over Pakistan both exceeding the threshold of the 90th percentile simultaneously) twice as likely compared to assuming independence between the two events. We quantify the influence of different previously proposed drivers ${ }^{8,40,45}$ in increasing the probability of occurrence of the 2010 summer extreme events. 2010 SST anomalies combined with radiative forcings have a large effect in increasing both surface temperature anomalies in western Russia and rainfall anomalies in Pakistan. Exceeding the 90th percentile temperature anomalies in western Russia increases 2-fold in the 2010 ensemble compared to the 1987-2015 


\section{Ensemble mean - 24.07-08.08 2010}

(a) SAT (K)

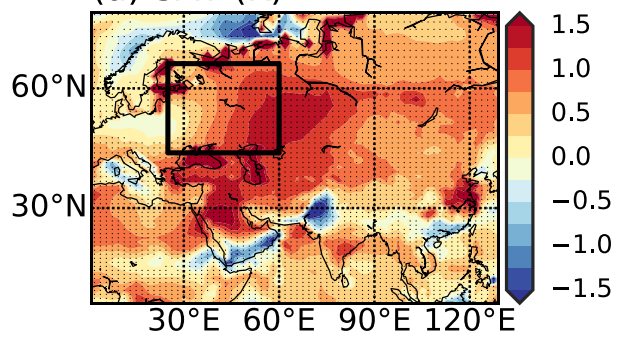

(c) Rainfall (Glob.) ( $\mathrm{mm} / \mathrm{d})$

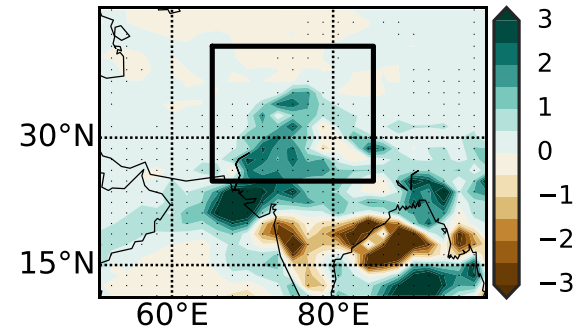

(e) Rainfall (Reg.) ( $\mathrm{mm} / \mathrm{d})$

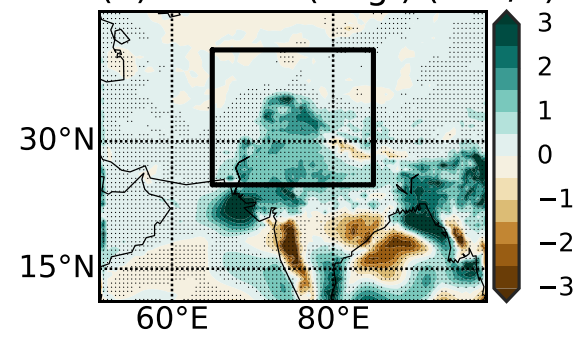

(g) $Z 300(\mathrm{~m})$ b) WRussia SAT

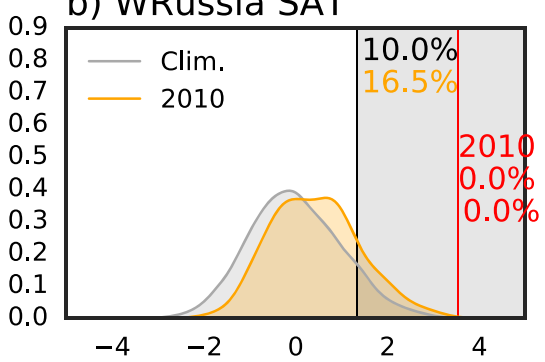

d) Pakistan Rainfall (Glob.)
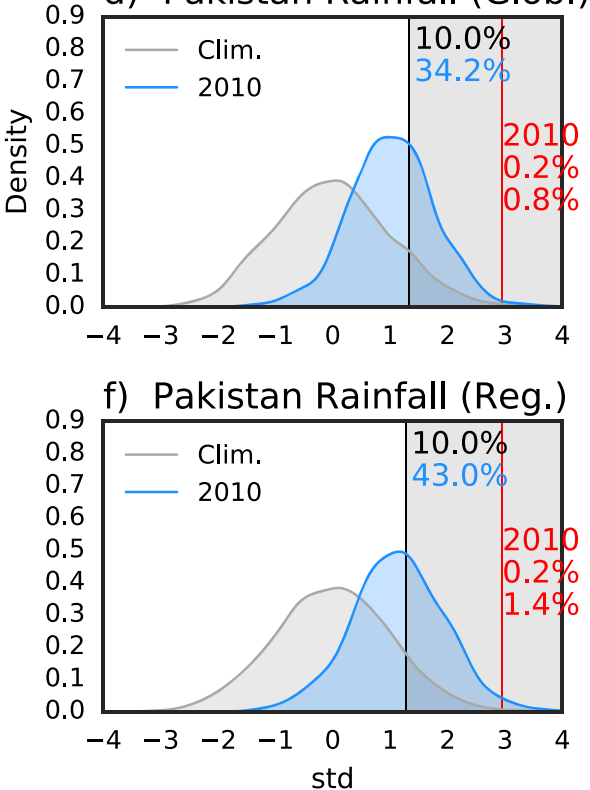
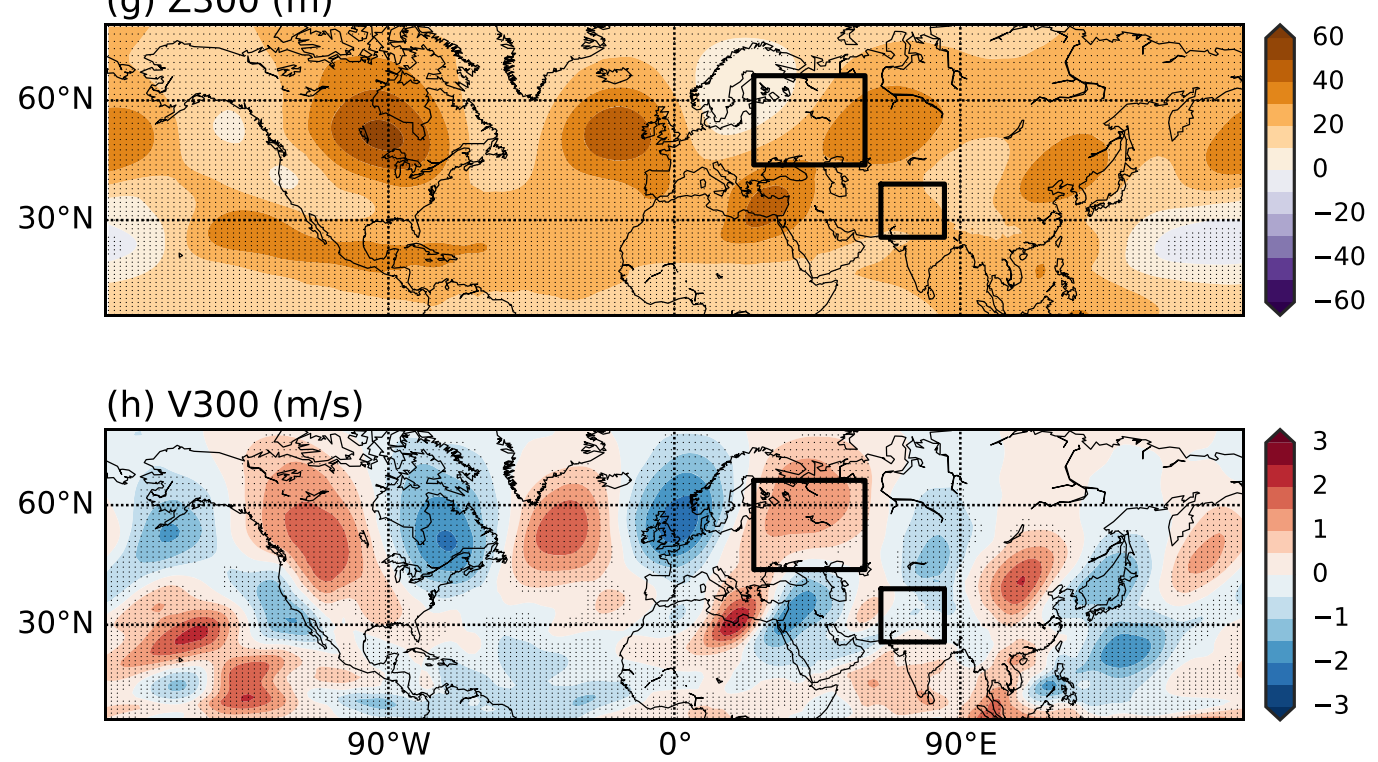

climatology of the model, while Pakistan rainfall anomalies increase up to four times. However, the experimental setup does not allow for a strict separation between direct GHG-induced versus SST-driven changes. High-latitude land warming i.e. enhanced surface temperature anomalies centered around $65^{\circ} \mathrm{N}$ in the Northern Hemisphere, further increases the probability of such extremes up to 2,5-fold (for temperature anomalies in western Russia) and 5-fold (for Pakistan rainfall anomalies). Drier than usual soils in western Russia in June lead to a similar quantitative increase of both extremes. Thus, low soil moisture 
Fig. 4 Weather@home 2010 ensemble mean. Panel a: ensemble mean of SAT anomaly for the period 24.07-08.08 for Glob2010. Note that the apparent date mismatch relative to observations stems from the fact that weather@home uses a 360 days calendar. Panel b: PDF for standardized WRussia SAT index for GlobClim (solid black line) and for Glob2010 (solid orange line). Using standardized indices helps to correct for model biases for a better comparison with observation. Panel c: Same as for panel a but for Rainfall anomalies over the Indian subcontinent for Glob2010. Panel d: PDF for standardized Pakistan Rainfall index for GlobClim (solid gray line) and Glob2010 (solid blue line). Panels e and f: Same as panels $\mathbf{c}$ and d for Rainfall anomalies in Reg2010 and RegClim. Vertical lines in panels b, d, and $\mathbf{f}$ show the climatological 90th percentile threshold (black line) and the 2010 threshold (red line) together with the percentage of ensemble members exceeding each threshold in the climatology (upper value) and in the 2010 ensemble (lower value). Panel g: ensemble mean for Z300 anomalies from Glob2010. Panel h: Same as for Panel $\mathbf{g}$ but for V300 anomalies from Glob2010. Anomalies are calculated as the deviation from GlobClim and RegClim ensemble means. The stippling represents significant grid points at $a=0.05$ and is calculated applying a Student- $t$ Test. The smoothing of the curve is done using a Gaussian kernel to produce continuous density estimates.

conditions in late spring and early summer over Russia represent a potential driver for enhancing both local surface temperatures and remote rainfall over Pakistan. Consistent with that, the probability of concurrent extremes becomes four times higher in the 2010 ensemble and grows even further when high latitude land warming or dry soils are considered (to about a 7-fold increase). This thus captures the combined, potentially nonlinear, effect of both 2010 SST and radiative forcings plus anomalous soil moisture conditions or high-latitude land warming conditions. Thus, the influence of soil moisture and high-latitude land warming, as determined here, is specific for the 2010 SST background state, and cannot necessarily be generalized to the entire climatology. Similar conclusions regarding the roles of SST, high-latitude warming, and soil moisture, can be drawn both for single and concurrent extremes, highlighting the important role of the wave train in those events.

A characteristic feature of 2010 was the La Niña-like SST anomaly in the tropical Pacific. Warm SST anomalies in the Indian Ocean have also contributed to increased low-level moisture content, possibly fueling rainfall activity in the Indian summer monsoon (ISM) region ${ }^{51}$. La Niña-like SST patterns affect ISM rainfall by shifting the region of strong convection related to the Walker circulation cell closer to Southeast Asia, enhancing the ISM circulation cell ${ }^{52,53}$. The most active center of ISM rainfall is usually located over central India, in a region where the monsoon trough is located $\left(\sim 25^{\circ} \mathrm{N}, 80^{\circ} \mathrm{E}\right)^{54,55}$. However, Fig. 4 shows that in the 2010 ensemble mean, rainfall is displaced towards the Indus river basin, instead of over the monsoon trough region, as seen in observations (Fig. 2). Hence, the 2010 Pakistan rainfall anomalies cannot be understood only as a deterministic response to 2010 SST patterns and radiative forcings. Complementary analysis is performed on GlobClim for La Niña and El Niño years. Composites of La Niña minus El Niño years show that selecting high-latitude land warming or enhanced Pakistan Rainfall higher than 90th quantile of the full GlobClim ensemble leads to higher than usual SAT anomalies over western Russia and enhanced rainfall anomalies in Pakistan during La Niña years (see Supplementary Figs. 12 and 13).

Extreme rainfall events on the western Himalayan foothills, such as the 2010 Pakistan flood, have been linked to a combination of a mid-tropospheric trough and associated dry and colder air intruding into the mid-to-low troposphere in the Indian subcontinent from higher latitudes combined with local orographic features ${ }^{56}$. Here, though we do not analyze the V-wind component in the lower troposphere, both observations and model simulations show a trough in $300 \mathrm{hPa}$ geopotential heights located northwest of the Pakistan region (Figs. 1e and $5 \mathrm{e}$, respectively). This trough is part of a mid-latitude wave train stretching from the eastern North Atlantic through Europe and western Russia towards the Indian subcontinent. Thus, model simulations can reproduce the atmospheric circulation pattern linking these two extreme events, and their concurrent probability is higher than that of independent events.

Previous studies showed that soil moisture can act as a Rossby wave source ${ }^{43}$, influencing the severity of temperature extremes in the mid-latitudes ${ }^{57,58}$. Here, we show that local soil moisture conditions can not only increase the probability of local heat extremes but also that of remote rainfall extremes, in this case, Pakistan. The link from drier-than-usual soils in western Russia in June to higher-than-usual temperatures in the same region is straightforward: low soil moisture values reduce evapotranspiration and cloudiness, further enhancing the warming ${ }^{5}$. The link between high temperatures over western Russia and enhanced rainfall over Pakistan can be explained by the connecting wave train. Soil moisture feedbacks thus likely strengthen the blocking over Russia by heating the atmospheric column ${ }^{4,41}$, generating a downstream response of enhanced cold air advection southwards towards Pakistan, which is instrumental in producing massive rainfall with a lead time of one month (see the "Methods" section). We analyze the soil moisture effect with one month lead time is, contemporaneously, the blocking over Russia could intensify due to a large-scale dynamical process (e.g. highlatitude land warming), and lead to both intensified soil drying locally and southward cold air advection toward Pakistan. In this case, although the two extreme events would result as correlated, one would not have caused the other. Finally, taking into account high-latitude land warming in the Northern Hemisphere as defined by Mann et al. $(2018)^{40}$, reveals that increased temperatures in high-latitudes also increase the probability of occurrence of both extremes. However, the exact causal chain here is less clear. On one hand, high-latitude land warming may be detected as a consequence of the wave pattern that transports additional heat northwards. Alternatively, high-latitude warming itself might change the characteristics of the wave pattern. For example, while the wave-train might be mostly driven by SSTs and local soilmoisture anomalies, its persistence might increase due to enhanced warming in high latitudes. More research is needed to disentangle these aspects.

How the potential drivers of weather extremes over Eurasia, as identified in this study, may change in the future is still an open question. The Indian summer monsoon precipitation is projected to increase under global warming ${ }^{12,59}$. The ENSO response to climate change is uncertain: while observations suggest a La Niñalike warming trend in central-western Pacific SST ${ }^{37,60}$, some studies indicate that in the long run, an El Niño-like pattern might dominate ${ }^{61,62}$. However, a recent study suggests that the La Niña-like trend might in fact be GHG forced and the El Niño-like tendency shown by future projections may be bias-induced ${ }^{63}$. Global warming may also intensify the summer drying of soils and the corresponding modulation of heatwaves and potentially wave trains ${ }^{44-46}$. Finally, high-latitude land warming is projected to increase under climate change ${ }^{64}$ and thus may contribute to heat extremes in mid-latitude regions and to extreme rainfall events over the western Himalayan region. The concurrent nature of these two extremes, as shown in our experiment, might imply enhanced societal risks in vulnerable regions ${ }^{9}$.

The weather@home models have shown its suitability to conduct climate simulations and attribution studies on several weather extremes such as the 2010 Russian heatwave, Australian wildfires in 2018, extreme rainfall events in Bangladesh, the 2017 


\section{Concurrent extremes - 24.07-08.08 2010}

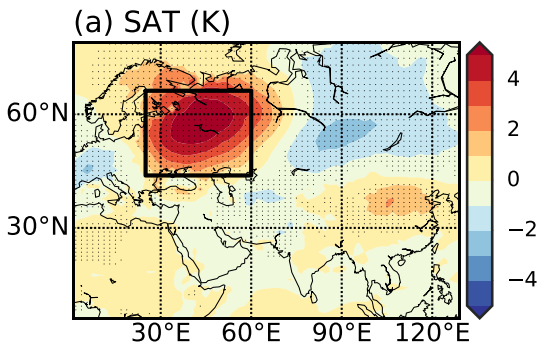

(c) Rainfall (Glob.) ( $\mathrm{mm} / \mathrm{d})$

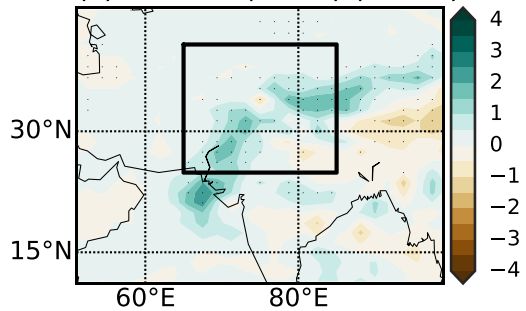

(d) Rainfall (Reg.) (mm/d)

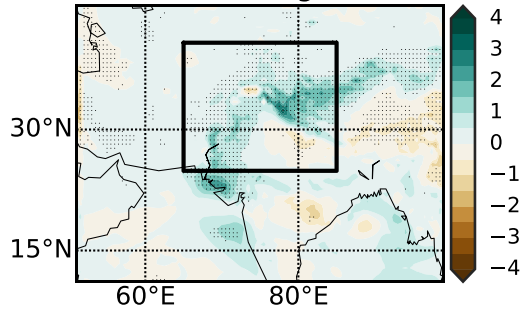

b) Joint probability
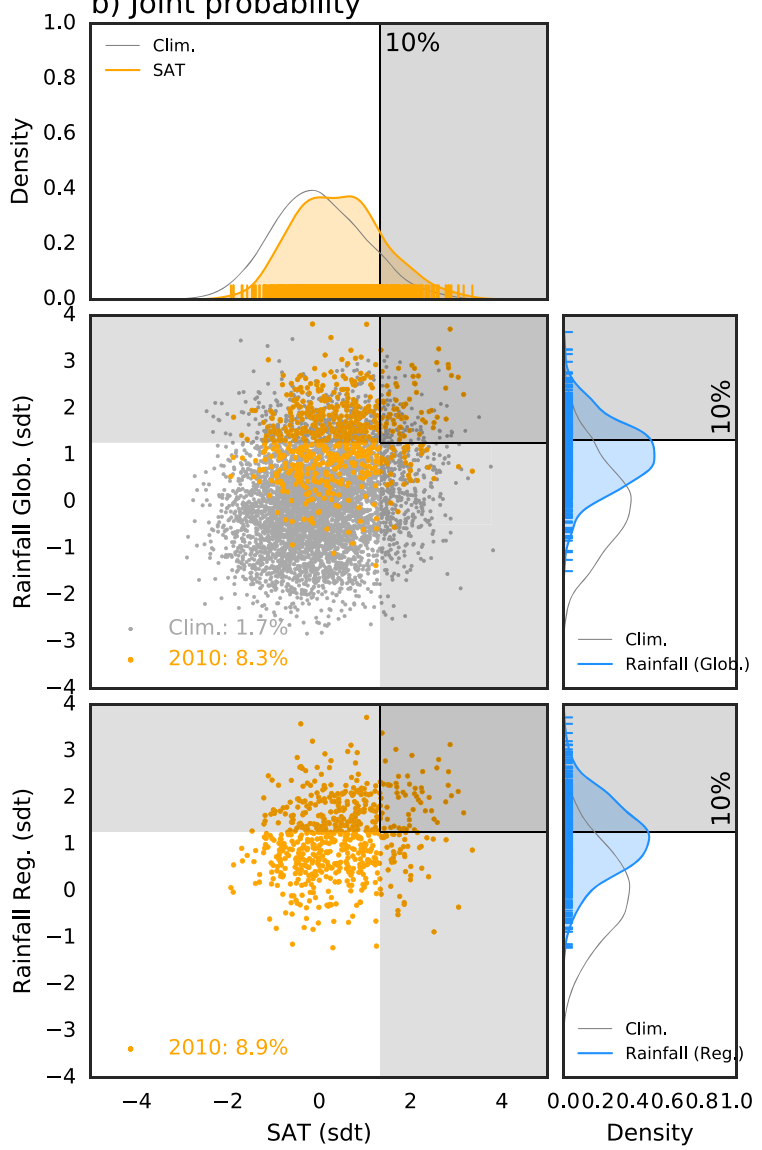

(e) $Z 300(\mathrm{~m})$
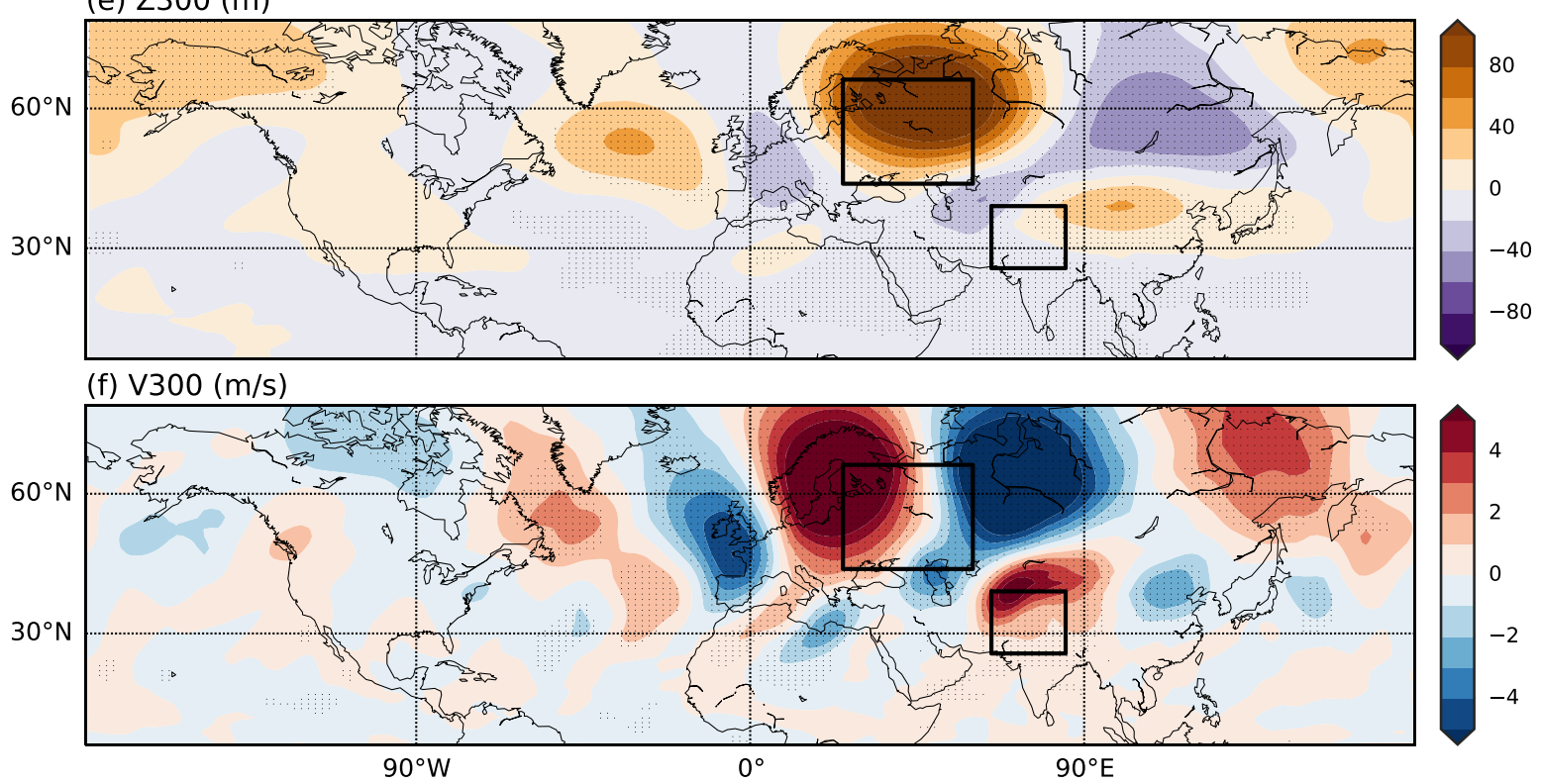

Chinese heatwave, and real-time extreme weather event attribution ${ }^{49,65-68}$. Despite the presence of a warm bias in mid-latitudes, the global model (HadAM3P) is reliable in most regions, and in terms of year-to-year variability in global temperature over land $^{69,70}$. Moreover, in this experiment, weather@home, is able to reproduce the circulation pattern that characterizes these extreme events, thus giving additional confidence in the performance of the model.

In conclusion, we have shown that the weather@home model can reproduce the atmospheric circulation pattern which led to the 
Fig. 5 Recurrent wave connecting 2010 extremes in weather@home. Panel a: composite of Glob2010 SAT over Eurasia for the period 24.07-08.08 (anomalies from Glob2010 ensemble mean for the same period) obtained by selecting those ensemble members that show both WRussia SAT (Glob2010) and Pakistan Rainfall (Reg2010) indices above the 90th percentile, i.e. the concurrent events. Panel b: PDF for WRussia SAT index in Glob2010 (solid orange line, top). PDF for Pakistan Rainfall index in Glob2010 (solid blue line, middle right) and scatter plot (middle left) of Pakistan Rainfall index on WRussia SAT for GlobClim (gray dots) and for Glob2010 ensemble (orange dots). PDF for Pakistan Rainfall index in Reg2010 (solid blue line, bottom right) and scatter plot (bottom left) of Pakistan Rainfall index on WRussia SAT for Reg2010 (orange dots). Black lines show the 90th percentile both in the PDFs and in the scatter plot and highlight the concurrent events in the top right gray-shaded panels in each scatter plot. Panels c and d: Same as for Panel a but showing composites of Glob2010 and Reg2010 Rainfall, respectively. Panel e: composite of Glob2010 Z300 for the period 24.07-08.08 (anomalies from Glob2010 ensemble mean for the same period) obtained by selecting those ensemble members that show both Glob2010 WRussia SAT and Reg2010 Pakistan Rainfall indices above the 90 th percentile. Panel f: Same as for Panel e but for V300. The stippling represents significant grid points at $a=0.05$ and is calculated applying a Student-t-test. The smoothing of the curve is done using a Gaussian kernel to produce continuous density estimates.

High-latitude land warming $\left(90^{\text {th }}\right)$ - contemporaneous - 24.07-08.08 2010

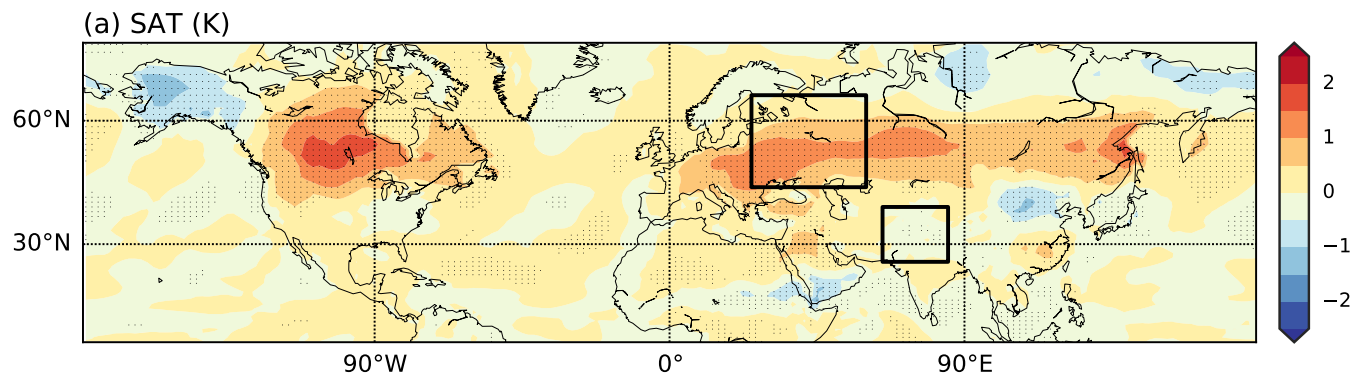

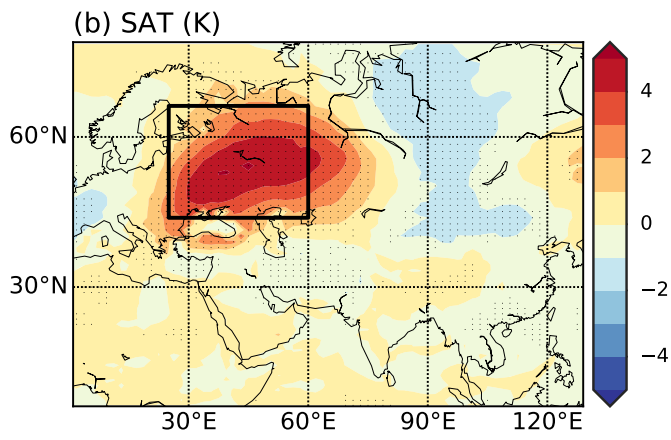

(d) Rainfall (Reg.) ( $\mathrm{mm} / \mathrm{d})$

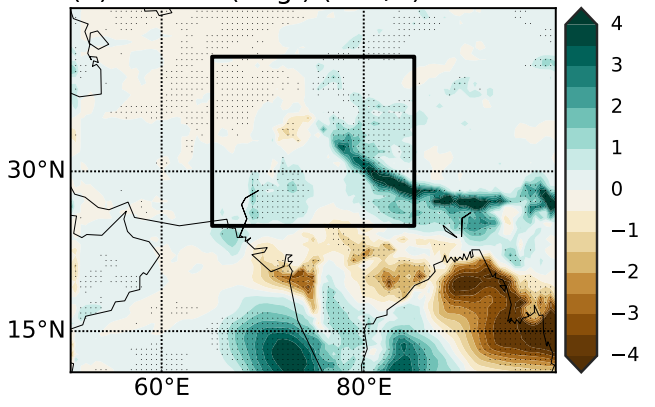

c) WRussia SAT

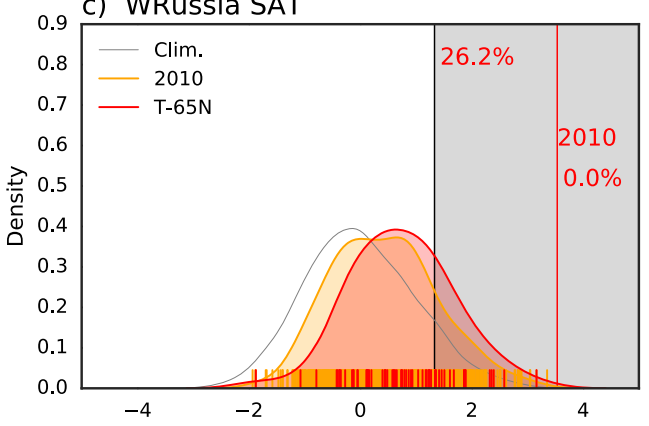

e) Pakistan Rainfall

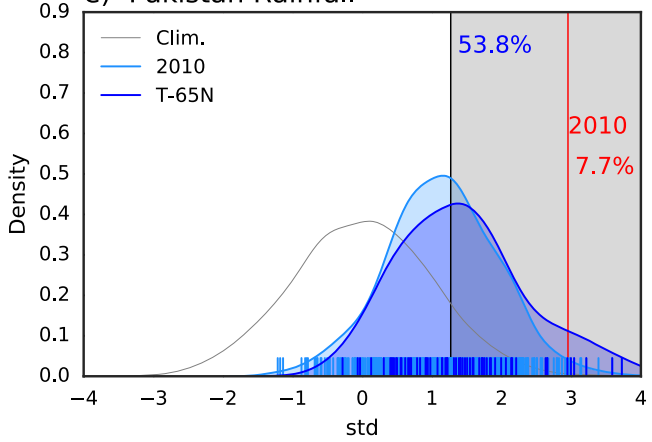

Fig. 6 W@H High-latitude land warming. Panel a: composites of SAT for ensemble members for Glob2010|T65N (exceeding the 90th percentile, 65 ensemble members out of 649) showing high-latitude land warming. Panel b: composites of SAT for Glob2010 | T65N (exceeding the 90th percentile) and also exceeding the 90th WRussia SAT index (GlobClim) percentile (black solid line in panel c). Panel c: PDF of WRussia SAT index for Glob2010 (orange solid line), for Glob2010| T65N (red solid line), and for GlobClim (gray solid line). The rug shows the exact position of the data, which are smoothened in the PDF using a Gaussian kernel to produce continuous density estimates. Panel d: composites of Rainfall for Reg2010 |T65N (exceeding the 90th percentile) and also exceeding the 90th Pakistan Rainfall (RegClim) percentile (black solid line in Panel e). Panel e: PDF for Pakistan Rainfall index in Reg2010 (solid light blue line), for Reg2010|T65N (blue solid line) and for RegClim (gray solid line). Both in panels $\mathbf{c}$ and e vertical solid black lines show the 90th percentile calculated from the climatological PDF and vertical solid red lines show the 2010 threshold (expressed in units of s.d.), together with the percentage of events that exceed this threshold in the T-65N sub-selection. Anomalies are calculated based on the Glob2010 (or Reg2010 for Rainfall) ensemble mean to differentiate from the impact of 2010 global SST. The stippling represents significant grid points at $a=0.05$ and is calculated applying a Student- $t$ test. 
(a) Soil Moisture $\left(\mathrm{kg}^{*} \mathrm{~m}^{-2}\right)$

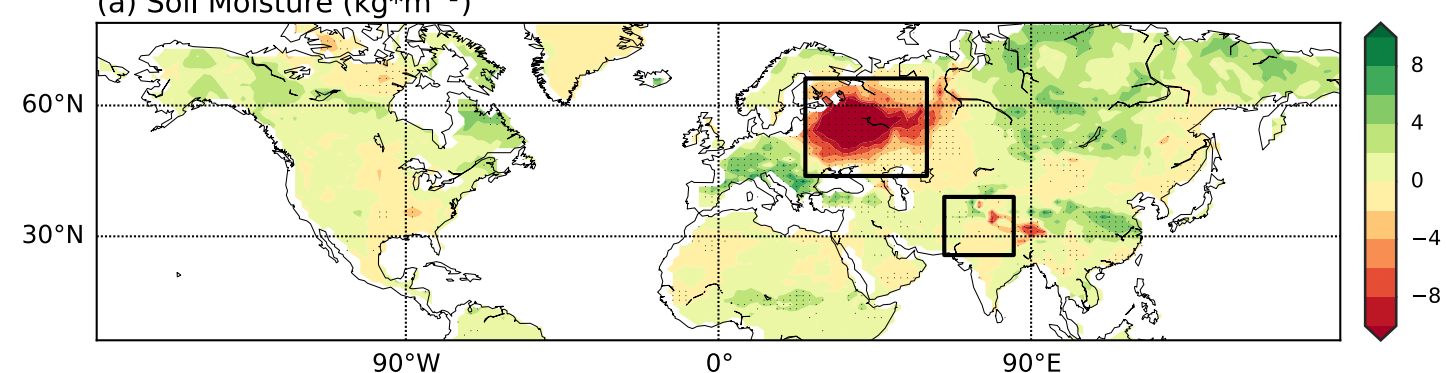

(b) SAT (K)

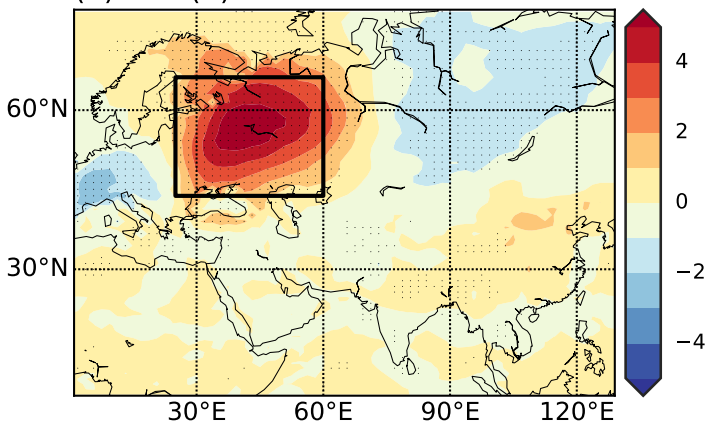

(d) Rainfall ( $\mathrm{mm} / \mathrm{d})$

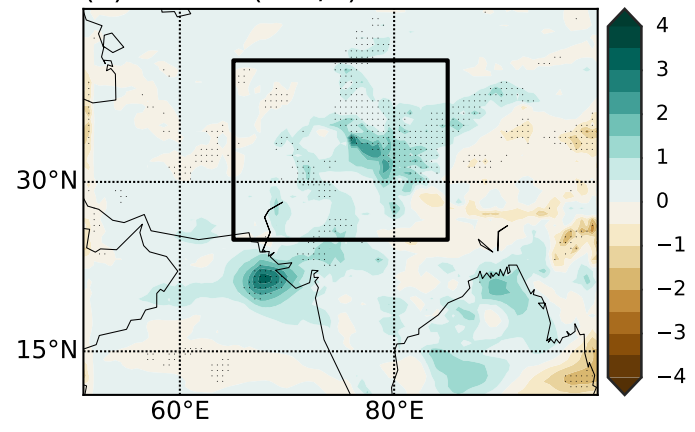

(c) WRussia SAT

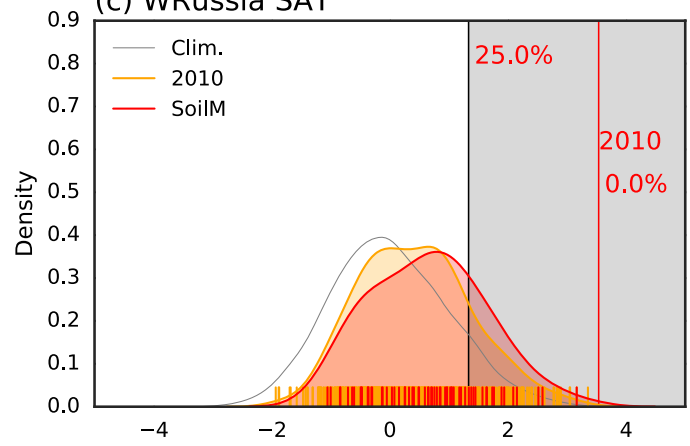

(e) Pakistan Rainfall

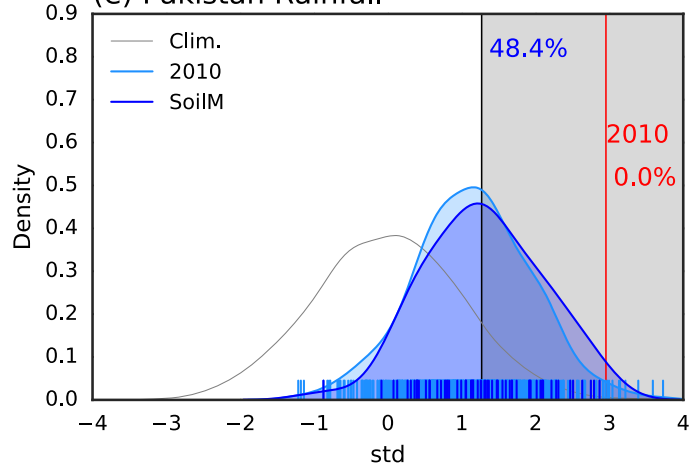

Fig. 7 Soil moisture in June. Panel a: composites of soil moisture for ensemble members selected with soil moisture signal over WRussia signal below the 10th percentile (65 ensemble members out of 649) during June (Glob2010| soilM). Panel b: composites of SAT for Glob2010| soilM and also exceeding the 90th WRussia SAT index (GlobClim) percentile (black solid line in panel c). Panel c: PDF of WRussia SAT index for Glob2010 (orange solid line) and for Glob2010 | soilM (red solid line). The rug shows the exact position of the data. Panel d: composites of regional Rainfall for Reg2010 | soilM and also exceeding the 90th Pakistan regional Rainfall index (RegClim) percentile (black solid line in Panel e). Panel d: PDF for Pakistan Rainfall index in Reg2010 (solid light blue line) and for Reg2010|soilM (blue solid line). Both in panels c and e vertical solid black line show the 90th percentile calculated from the climatological PDF and vertical solid red lines show the 2010 threshold (expressed in units of s.d.) together with the percentage of events that exceed this threshold in the soilM sub-selection. Anomalies are calculated based on the Glob2010 (or Reg2010 for Rainfall) ensemble mean to differentiate from the impact of 2010 global SST. The stippling represents significant grid points at $a=0.05$ and is calculated applying a Student- $t$ test. The smoothing of the curve is done using a Gaussian kernel to produce a continuous density estimates.

concurrent Russia-Pakistan extreme in summer 2010 and we have identified the influence of different drivers of those extremes. The climatological run of our modeling study shows that the probability of getting a concurrent event is almost twice as much as if the two events were independent. This probability increases 5 -fold when the 2010 year is simulated, highlighting the importance of the $2010 \mathrm{La}$ Niña-like SST. Moreover, contemporaneous high-latitude land warming further increases the probability both of single events and of concurrent events. Drier than normal local soil moisture features over western Russia are found to increase the probability of the extreme event with a time lag of approximately one month. Thus, the combination of SST anomalies, high-latitude land warming, and low soil moisture, favors the occurrence of the atmospheric wave train leading to the concurrent Russian heatwave and Pakistan flooding. These findings highlight the complexity and dependencies behind such persistent wave trains and high-impact extremes within our highly interconnected and dynamical climate system.

\section{METHODS}

\section{Observational data}

To characterize the atmospheric conditions related to the Russian heatwave and the Pakistan flood, we use $1.5^{\circ} \times 1.5^{\circ}$ surface atmospheric temperature at $2 \mathrm{~m}$ (SAT), meridional wind component at $300 \mathrm{hPa}$ (V300) and geopotential 
a) Joint probability (Glob.)

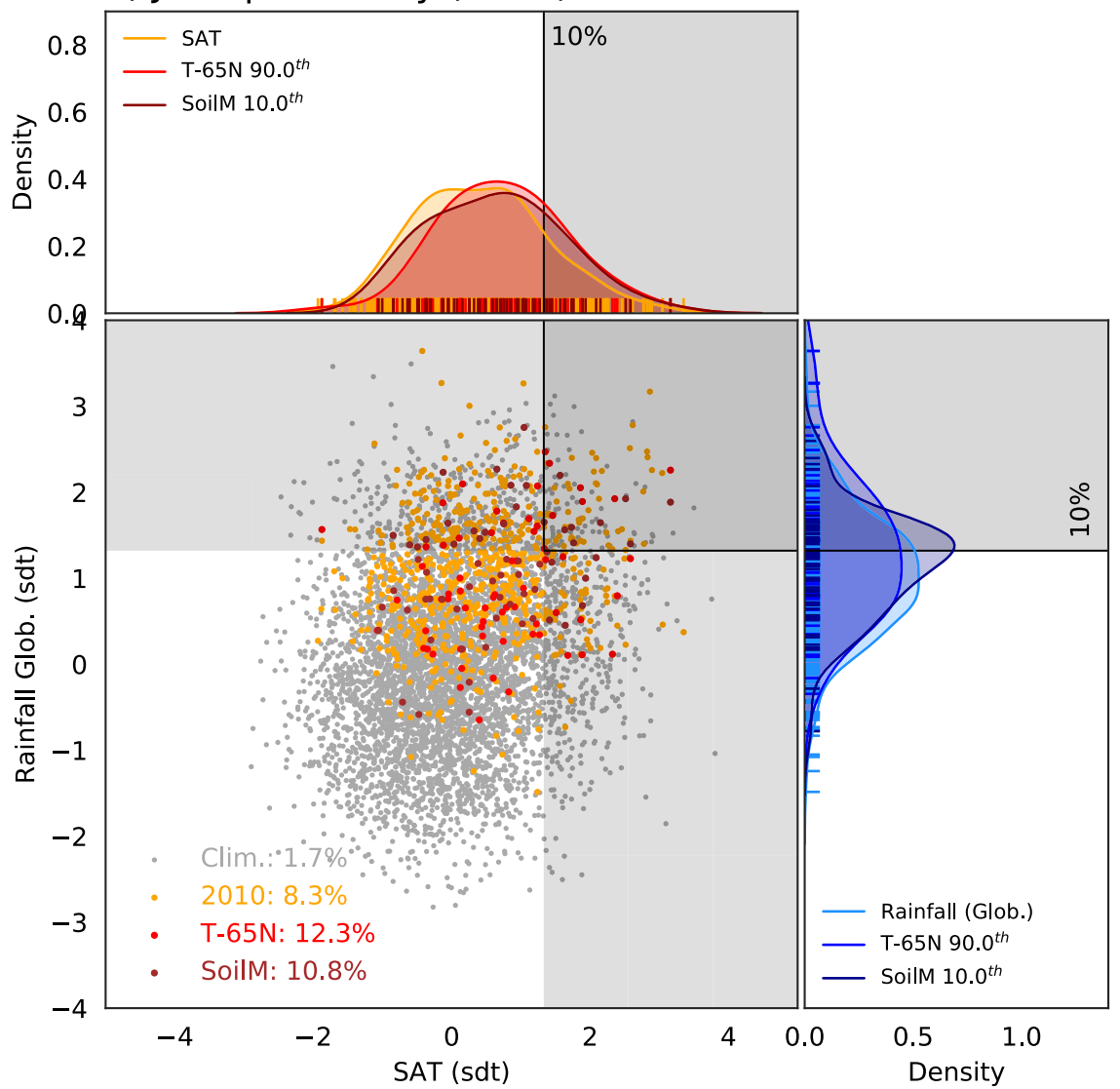

Fig. 8 Concurrent extremes, high-latitude land warming, and soil moisture. Top panel: PDF for WRussia SAT index in Glob2010 (solid orange line), Glob2010|T65N (solid red line) and Glob2010 | soilM (solid brown line). The black solid line shows the $90^{\text {th }}$ WRussia SAT index (GlobClim) percentile. Bottom right panel: PDF for Pakistan Rainfall index in the 2010 ensemble (solid light blue line), Glob2010|T65N (solid blue line), and Glob2010 | soilM (solid dark blue line). The black solid line shows the 90th Pakistan Rainfall index (GlobClim) percentile. Bottom left panel: scatter plot of Pakistan global Rainfall index on WRussia SAT for the GlobClim (gray dots, 4930 ensemble members), for the Glob2010 (orange dots, 649 ensemble members, of which 54 exceeding the 90th quantile for both WRussia SAT and Pakistan Rainfall indices), for Glob2010 |T65N (red dots, 65 ensemble members of which 8 also exceeding the 90th quantile for both WRussia SAT and Pakistan Rainfall indices) and Glob2010| soilM (brown dots, 65 ensemble members, of which 7 also exceeding the 90th quantile for both WRussia SAT and Pakistan Rainfall indices). Concurrent events are highlighted in the top right gray-shaded area. Note that percentages for T-65N and SoilM are calculated by comparing the number of concurrent events that show T-65N (8) and SoilM (7) with the total number of T-65N and SoilM events in Glob2010 (65 each). The smoothing of the curve is done using a Gaussian kernel to produce continuous density estimates.

height at $300 \mathrm{hPa}(\mathrm{Z300})$ data from ERA-Interim Reanalysis ${ }^{71}$ and $0.25^{\circ} \times 0.25^{\circ}$ rainfall data from the CPC/NCEP ${ }^{72}$ averaged over the period $25.07-08.08 .2010$. Anomalies are calculated based on the 1987-2015 climatology of 25.07-08.08 averages, consistent with the available weather@home climatology.

\section{Weather@home/climatepredicition.net}

The weather@home system runs on a volunteer distributed computing network provided by the climateprediction.net project. weather@home uses the HadAM3P atmospheric model developed by the UK Met Office Hadley Centre ${ }^{73,74}$. HadAM3P is forced by observed SST, sea ice fractions, well-mixed GHG concentrations, volcanic activity, and solar forcing and has a resolution of $1.25^{\circ} \times 1.875^{\circ 69}$. The model is also forced by observed aerosols $\left(\mathrm{SO}_{2}\right.$ and atmospheric dimethyl sulfide) but it does not include black carbon. The regional version, HadRM $3 \mathrm{P}$, uses HadAM3P as boundary forcing and has a finer spatial resolution $\left(0.44^{\circ} \times 0.44^{\circ}\right)$ for improved simulation of mesoscale features and orographic precipitation. For a detailed description of the weather@home model and for more information on its performance, biases and applications see further references ${ }^{49,69,70}$.

\section{0 model experiments}

The large ensemble consists of 649 ensemble members for both the HadAM3P (from now on referred to as Glob2010) and HadRM3P (referred to as Reg2010) models. Each ensemble member starts in December 2008 and runs till September 2010. From Glob2010, we analyze geopotential height at $300 \mathrm{hPa}$ (Z300), zonal and meridional winds at $300 \mathrm{hPa}$ (U300 and V300, respectively), the surface atmospheric temperature at $1.5 \mathrm{~m}$ (SAT), and soil moisture (soilM). Note that ERA-Interim SAT is calculated at $2 \mathrm{~m}$, however, defining SAT at this slightly higher level is not expected to make a material difference. Rainfall is available from both Reg2010 and Glob2010 simulations. All variables are available at daily resolution for both Glob2010 and Reg2010 with the only exception of soilM, which is provided on a monthly time scale. To reduce the noise associated with precipitation data, 3-day running means of both Glob2010 and Reg2010 Rainfall output are taken. The climatology of both regional and global models is calculated over the period 1987-2015 (for a total of 29 years) and hereafter referred to as GlobClim and RegClim. Each year in GlobClim (RegClim) has 170 (99) ensemble members, leading to a total of 4930 (2871) years. Figure 2 shows a schematic of the model experiment setups together with their corresponding labels.

Both Glob2010 and Reg2010 ensembles are forced by observed SST and radiative forcing agents. The pattern of observed SST trends in the past decades, induced by the GHG forcing, resembles the La Niña SST anomaly pattern (Supplementary Fig. 2) 37,60 . However, our model setup does not allow for a thorough assessment of the effect of GHG and SST forcing separately. In the following, we calculate anomalies by subtracting the Glob2010 (or Reg2010) ensemble average (thus removing the SST/GHG effect) and show both anomalies and ensemble means. Each 
Reg2010 simulation is driven by an associated Glob2010 simulation, but the RegClim simulations were driven by different global simulations not part of the GlobClim ensemble used here. Hence, while for Glob2010 and Reg2010 it is possible to select a set of ensemble members in Glob2010 and select the corresponding ensemble members in Reg2010 (or vice versa), this is not possible between GlobClim and RegClim (for more detailed information see Supplementary Discussion 1).

\section{High-latitude land warming}

From the Glob2010 and Reg2010 ensembles, we make two sub-selections of ensemble members that meet specific characteristics. The first subselection consists of those ensemble members showing enhanced warming over land in high-latitudes $\left(\sim 65^{\circ} \mathrm{N}\right)$ in the Northern Hemisphere. We define high-latitude land warming (abbreviated as T65N) following Mann et al. (2018) that introduces a metric based on surface air temperature to identify QRA events. Observed QRA events are diagnosed by peaks in zonal SAT profiles around $\sim 65^{\circ} \mathrm{N}$, labeled as climatological $Q R A$ fingerprint (see Supplementary Fig. 14). Here, we calculate the contemporaneous (lead zero) correlation between the QRA fingerprint and the zonal SAT profile from the Glob2010 ensemble. Those ensemble members that are characterized by high correlation values (above the 90th percentile $=r_{90 t h}=0.72$, where $r_{\min }=-0.61$ and $r_{\max }=0.90$ ) are selected for the "high-latitude land warming" sub-selection (Glob2010|T65N and Reg2010|T65N).

\section{Soil moisture}

The second sub-selection of Glob2010 and Reg2010 ensemble members is applied using local soil moisture characteristics over western Russia. First, we calculate the monthly soil moisture (soilM) index by averaging over the region of the western Russia heatwave $\left(45^{\circ}-65^{\circ} \mathrm{N}, 25^{\circ}-60^{\circ} \mathrm{E}\right)$ from the Glob2010 ensemble. Then, ensemble members that show soilM values lower than the 10th percentile in the month of June are included in these sub-selections as Glob2010|soilM and Reg2010|soilM. Thus, the soil moisture signal is detected one month in advance (one month lead) with respect to the target variable, which is detected at the end of July/ beginning of August.

\section{Temperature and rainfall indices}

An index for the western Russia heatwave is defined, both in observations and model experiments, by applying a spatial average of SAT over western Russia $\left(45^{\circ}-65^{\circ} \mathrm{N}, 25^{\circ}-60^{\circ} \mathrm{E}\right)$. Similarly, the Pakistan flood is defined by averaging rainfall over the Pakistan/western Himalayan foothills region $\left(25^{\circ}-40^{\circ} \mathrm{N}, 65^{\circ}-85^{\circ} \mathrm{E}\right)$. Following Lau and Kim (2011), all indices are temporally averaged in the period 24.07.10-08.08.10 (starting on the 24.07 instead of 25.07 since the model uses a 360 days calendar), obtaining one index in each region for each ensemble member. We will refer to these indices as to WRussia SAT and Pakistan Rainfall indices, respectively. To account for model biases both indices are standardized by removing the climatological mean and dividing by their respective standard deviation derived from the 1987-2015 climatology. Extreme heat events over western Russia are defined as ensemble members where the WRussia SAT index exceeds the 90th (climatological) percentile threshold. Similarly, extreme rainfall events over Pakistan are defined as those ensemble members where the Pakistan Rainfall index exceeds the 90th (climatological) percentile threshold. Concurrent events are defined as those ensemble members where both the WRussia SAT index and the Pakistan rainfall index exceed their respective climatological 90th percentile thresholds simultaneously.

\section{DATA AVAILABILITY}

The model output data for the experiment used in this study is freely available at the Centre for Environmental Data Analysis (https://catalog.ceda.ac.uk/uuid/ dae723e78f9f4a0b9712f352f0a0231d). Data can be cited as: Sparrow, S.; Wallom, D.; Di Capua, G.; Rousi, E.; Kornhuber, K.; van der Hurk, B.; Coumou, D.; Osprey, S. (2021): weather@home 2010 global simulations and climatology (1986-2016). NERC EDS Centre for Environmental Data Analysis, 08 September 2021. https://doi.org/ 10.5285/dae723e78f9f4a0b9712f352f0a0231d.

\section{CODE AVAILABILITY}

The $\mathrm{R}$ and python code used to run the analysis is stored on the PIK cluster and can be obtained upon request to the first author.

Received: 14 January 2021; Accepted: 29 September 2021; Published online: 04 November 2021

\section{REFERENCES}

1. Lau, W. K. M. \& Kim, K.-M. The 2010 Pakistan flood and Russian heat wave: teleconnection of hydrometeorological extremes. J. Hydrometeorol. 13, 392-403 (2011).

2. Houze, R. A., Rasmussen, K. L., Medina, S., Brodzik, S. R. \& Romatschke, U. Anomalous atmospheric events leading to the summer 2010 floods in Pakistan. Bull. Am. Meteorol. Soc. 92, 291-298 (2011).

3. Barriopedro, D., Fischer, E. M., Luterbacher, J., Trigo, R. M. \& García-Herrera, R. The hot summer of 2010: redrawing the temperature record map of Europe. Science (80-.) 332, 220-224 (2011).

4. Miralles, D. G., Teuling, A. J., Van Heerwaarden, C. C. \& De Arellano, J. V. G. Megaheatwave temperatures due to combined soil desiccation and atmospheric heat accumulation. Nat. Geosci. 7, 345-349 (2014).

5. Dole, R. et al. Was there a basis for anticipating the 2010 Russian heat wave? Geophys. Res. Lett. 38, 1-5 (2011).

6. Schneidereit, A. et al. Large-scale flow and the long-lasting blocking high over Russia: Summer 2010. Mon. Weather Rev. 140, 2967-2981 (2012).

7. Trenberth, K. E. \& Fasullo, J. T. Climate extremes and climate change: the Russian heat wave and other climate extremes of 2010. J. Geophys. Res. Atmos. 117, n/ a-n/a (2012).

8. Priya, P., Mujumdar, M., Sabin, T. P., Terray, P. \& Krishnan, R. Impacts of IndoPacific Sea surface temperature anomalies on the summer monsoon circulation and heavy precipitation over northwest India-Pakistan region during 2010. J. Clim. 28, 3714-3730 (2015).

9. Kornhuber, K. et al. Amplified Rossby waves enhance risk of concurrent heatwaves in major breadbasket regions. Nat. Clim. Chang. 20, 48-53 (2020).

10. Westra, S. et al. Future changes to the intensity and frequency of short-duration extreme rainfall. Rev. Geophys. 59, 522-555 (2014).

11. Lehmann, J., Coumou, D. \& Frieler, K. Increased record-breaking precipitation events under global warming. Clim. Chang. 501-515 https://doi.org/10.1007/ s10584-015-1434-y (2015).

12. Turner, A. G. \& Annamalai, H. Climate Change and the south Asian summer monsoon. Nat. Clim. Chang 2, 587-595 (2012).

13. Westra, S., Alexander, L. V. \& Zwiers, F. W. Global increasing trends in annual maximum daily precipitation. J. Clim. 26, 3904-3918 (2013).

14. Zhang, X., Wan, H., Zwiers, F. W., Hegerl, G. C. \& Min, S. K. Attributing intensification of precipitation extremes to human influence. Geophys. Res. Lett. 40, 5252-5257 (2013).

15. Asadieh, B. \& Krakauer, N. Y. Global trends in extreme precipitation: climate models versus observations. Hydrol. Earth Syst. Sci. 19, 877-891 (2015).

16. Horton, D. E. et al. Contribution of changes in atmospheric circulation patterns to extreme temperature trends. Nature 522, 465-469 (2015).

17. Shepherd, T. G. The dynamics of temperature extremes. Nature 522, 425-427 (2015).

18. Shepherd, T. G. Atmospheric circulation as a source of uncertainty in climate change projections. Nat. Geosci. 7, 703-708 (2014).

19. Coumou, D., Di Capua, G., Vavrus, S., Wang, L. \& Wang, S. The influence of Arctic amplification on mid-latitude summer circulation. Nat. Commun. 9, 2959 (2018).

20. Schubert, S., Wang, H. \& Suarez, M. Warm season subseasonal variability and climate extremes in the northern hemisphere: the role of stationary Rossby waves. J. Clim. 24, 4773-4792 (2011).

21. Lee, M. H., Lee, S., Song, H. J. \& Ho, C. H. The recent increase in the occurrence of a boreal summer teleconnection and its relationship with temperature extremes. J. Clim. 30, 7493-7504 (2017).

22. Kornhuber, K., Petoukhov, V., Petri, S., Rahmstorf, S. \& Coumou, D. Evidence for wave resonance as a key mechanism for generating high-amplitude quasi-stationary waves in boreal summer. Clim. Dyn. 49, 1961-1979 (2017).

23. Drouard, M. \& Woollings, T. Contrasting mechanisms of summer blocking over Western Eurasia. Geophys. Res. Lett. 45, 12,040-12,048 (2018).

24. Woollings, T. Dynamical influences on European climate: an uncertain future. Philos. Trans. R. Soc. A Math. Phys. Eng. Sci. 368, 3733-3756 (2010).

25. Pfleiderer, P., Schleussner, C. \& Coumou, D. Boreal summer weather becomes more persistent in a warmer world. Nat. Clim. Chang. https://doi.org/10.1038/ s41558-019-0555-0 (2018). 
26. Röthlisberger, M., Pfahl, S. \& Martius, O. Regional-scale jet waviness modulates the occurrence of midlatitude weather extremes. Geophys. Res. Lett. 43 10,989-10,997 (2016).

27. Di Capua, G. \& Coumou, D. Changes in meandering of the Northern Hemisphere circulation. Environ. Res. Lett. 11, 1-9 (2016).

28. Barnes, E. A. Revisiting the evidence linking Arctic amplification to extreme weather in midlatitudes. Geophys. Res. Lett. 40, 4734-4739 (2013).

29. O'Reilly, C. H., Woollings, T., Zanna, L. \& Weisheimer, A. The impact of tropical precipitation on summertime Euro-Atlantic circulation via a circumglobal wave train. J. Clim. 31, 6481-6504 (2018).

30. Wulff, C. O., Greatbatch, R. J., Domeisen, D. I. V., Gollan, G. \& Hansen, F. Tropical forcing of the summer East Atlantic Pattern. Geophys. Res. Lett. 44, 11,166-11,173 (2017).

31. Douville, H. et al. Tropical influence on boreal summer mid-latitude stationary waves. Clim. Dyn. 37, 1783-1798 (2011).

32. Trenberth, K. E. \& Guillemot, C. J. Physical processes involved in the 1988 drought and 1993 floods in North America. J. Clim. 9, 1288-1298 (1996).

33. Ding, Q. \& Wang, B. Circumglobal teleconnection in the Northern Hemisphere summer. J. Clim. 18, 3483-3505 (2005).

34. Ding, Q., Wang, B., Wallace, J. M. \& Branstator, G. Tropical-extratropical teleconnections in boreal summer: observed interannual variability. J. Clim. 24, 1878-1896 (2011).

35. Di Capua, G. et al. Tropical and mid-latitude teleconnections interacting with the Indian summer monsoon rainfall: a theory-guided causal effect network approach. Earth Syst. Dyn. 11, 17-34 (2020).

36. O'Reilly, C. H., Woollings, T., Zanna, L. \& Weisheimer, A. An interdecadal shift of the extratropical teleconnection from the tropical Pacific during boreal summer. Geophys. Res. Lett. https://doi.org/10.1029/2019gl084079 (2019).

37. Mujumdar, M. et al. The Asian summer monsoon response to the La Niña event of 2010. Meteorol. Appl. 19, 216-225 (2012).

38. Watanabe, M. et al. Event attribution of the August 2010 Russian heat wave. Sci. Online Lett. Atmos. 9, 65-68 (2013).

39. Petoukhov, V., Rahmstorf, S., Petri, S. \& Schellnhuber, H. J. Quasiresonant amplification of planetary waves and recent Northern Hemisphere weather extremes. Proc. Natl Acad. Sci. USA 110, 5336-5341 (2013).

40. Mann, M. E. et al. Projected changes in persistent extreme summer weather events: the role of quasi-resonant amplification. Sci. Adv. 4, 1-10 (2018).

41. Teng, H. \& Branstator, G. Amplification of waveguide teleconnections in the boreal summer. Curr. Clim. Chang. Rep. 5, 421-432 (2019).

42. Teng, H., Branstator, G., Tawfik, A. B. \& Callaghan, P. Circumglobal response to prescribed soil moisture over North America. J. Clim. 32, 4525-4545 (2019).

43. Koster, R. D., Chang, Y., Wang, H. \& Schubert, S. D. Impacts of local soil moisture anomalies on the atmospheric circulation and on remote surface meteorological fields during boreal summer: a comprehensive analysis over North America. J. Clim. 29, 7345-7364 (2016).

44. Seneviratne, S. I. et al. Investigating soil moisture-climate interactions in a changing climate: a review. Earth-Sci. Rev. 99, 125-161 (2010).

45. Seneviratne, S. I. et al. Impact of soil moisture-climate feedbacks on CMIP5 projections: first results from the GLACE-CMIP5 experiment. Geophys. Res. Lett. 40, 5212-5217 (2013).

46. Vogel, M. M. et al. Regional amplification of projected changes in extreme temperatures strongly controlled by soil moisture-temperature feedbacks. Geophys. Res. Lett. 44, 1511-1519 (2017).

47. Rasmijn, L. M. et al. Future equivalent of 2010 Russian heatwave intensified by weakening soil moisture constraints. Nat. Clim. Chang. 8, 381-385 (2018).

48. Hauser, M., Orth, R. \& Seneviratne, S. I. Role of soil moisture versus recent climate change for the 2010 heat wave in western Russia. Geophys. Res. Lett. 43 , 2819-2826 (2016).

49. Otto, F. E. L., Massey, N., Van Oldenborgh, G. J., Jones, R. G. \& Allen, M. R Reconciling two approaches to attribution of the 2010 Russian heat wave. Geophys. Res. Lett. 39, 1-5 (2012).

50. Kornhuber, K. et al. Extreme weather events in early summer 2018 connected by a recurrent hemispheric wave-7 pattern. Environ. Res. Lett. 14, 054002 (2019).

51. Martius, O. et al. The role of upper-level dynamics and surface processes for the pakistan flood of July 2010. Q. J. R. Meteorol. Soc. 139, 1780-1797 (2013).

52. Krishnamurthy, V. \& Goswami, B. N. Indian monsoon-ENSO relationship on interdecadal timescale. J. Clim. 13, 579-595 (2000).

53. Kripalani, R. H. \& Kulkarni, A. Climatic impact of El Niño/La Niña on the Indian monsoon: a new perspective. R. Meteorol. Soc. 52, 205-209 (1997).

54. Choudhury, A. D. \& Krishnan, R. Dynamical response of the South Asian Monsoon Trough to latent heating from stratiform and convective precipitation. J. Atmos. Sci. 68, 1347-1363 (2011)

55. Krishnan, R. \& Sugi, M. Pacific decadal oscillation and variability of the Indian summer monsoon rainfall. Clim. Dyn. https://doi.org/10.1007/s00382-003-0330-8 (2003)
56. Vellore, R. K. et al. Monsoon-extratropical circulation interactions in Himalayan extreme rainfall. Clim. Dyn. 46, 3517-3546 (2016).

57. Hirschi, M. et al. Observational evidence for soil-moisture impact on hot extremes in southeastern Europe. Nat. Geosci. 4, 17-21 (2010).

58. Fischer, E. M., Seneviratne, S. I., Vidale, P. L., Lüthi, D. \& Schär, C. Soil moisture-atmosphere interactions during the 2003 European summer heat wave. J. Clim. 20, 5081-5099 (2007).

59. Menon, A., Levermann, A., Schewe, J., Lehmann, J. \& Frieler, K. Consistent increase in Indian monsoon rainfall and its variability across CMIP-5 models. Earth Syst. Dyn. 4, 287-300 (2013).

60. Kohyama, T., Hartmann, D. L. \& Battisti, D. S. La Niña-like mean-state response to global warming and potential oceanic roles. J. Clim. 30, 4207-4225 (2017).

61. Xiang, B., Wang, B., Li, J., Zhao, M. \& Lee, J. Y. Understanding the anthropogenically forced change of equatorial pacific trade winds in coupled climate models. J. Clim. 27, 8510-8526 (2014)

62. An, S. I. L., Kim, J. W., Im, S. H., Kim, B. M. \& Park, J. H. Recent and future sea surface temperature trends in tropical pacific warm pool and cold tongue regions. Clim. Dyn. 39, 1373-1383 (2012).

63. Seager, R. et al. Strengthening tropical Pacific zonal sea surface temperature gradient consistent with rising greenhouse gases. Nat. Clim. Chang. 9, 517-522 (2019).

64. Mann, M. E. et al. Influence of anthropogenic climate change on planetary wave resonance and extreme weather events. Sci. Rep. 7, 45242 (2017).

65. Rimi, R. H. et al. Evaluation of a large ensemble regional climate modelling system for extreme weather events analysis over Bangladesh. Int. J. Climatol. 39, 2845-2861 (2019).

66. Lewis, S. C. et al. Deconstructing factors contributing to the 2018 fire weather in Queensland, Australia. Bull. Am. Meteorol. Soc. 101, S115-S122 (2020).

67. Sparrow, S. et al. Attributing human influence on the July 2017 Chinese heatwave: The influence of sea-surface temperatures. Environ. Res. Lett. 13, 114004 (2018).

68. Haustein, K. et al. Real-time extreme weather event attribution with forecast seasonal SSTs. Environ. Res. Lett. 11, 064006, (2016).

69. Massey, N. et al. Weather@Home-Development and validation of a very large ensemble modelling system for probabilistic event attribution. Q. J. R. Meteorol. Soc. 141, 1528-1545 (2015).

70. Guillod, B. P. et al. Weather@home 2: validation of an improved global-regional climate modelling system. Geosci. Model Dev. 10, 1849-1872 (2017).

71. Dee, D. P. et al. The ERA-Interim reanalysis: configuration and performance of the data assimilation system. Q. J. R. Meteorol. Soc. 137, 553-597 (2011).

72. Chen, M. et al. Assessing objective techniques for gauge-based analyses of global daily precipitation. J. Geophys. Res. Atmos. 113, 1-13 (2008).

73. Pope, V. D., Gallani, M. L., Rowntree, P. R. \& Stratton, R. A. The impact of new physical parametrizations in the Hadley Centre climate model: HadAM3. Clim. Dyn. 16, 123-146 (2000).

74. Gordon, C. et al. The simulation of SST, sea ice extents and ocean heat transports in a version of the Hadley Centre coupled model without flux adjustments. Clim. Dyn. 16, 147-168 (2000).

\section{ACKNOWLEDGEMENTS}

This work was supported by the German Federal Ministry of Education and Research (BMBF), grants 01LP1611A (G.D.C., E.R. and D.C.) and 01LP1901E (E.R.); the JPI Climate/JPI Oceans project ROADMAP (grant no. 01LP2002B) (G.D.C.); the Netherlands Organization for Scientific Research (NWO), grant 016.Vidi.171011 (D. C.); the National Science Foundation NSF AGS-1934358 (K.K.); the Belmont-Forum funded GOTHAM project (NE/P006779/1) (S.S., D.W., and S.O.) and the UK NERC National Centre for Atmospheric Science (S.O.). We would like to thank the Met Office Hadley Centre PRECIS team for their technical and scientific support for the development and application of weather@Home. Finally, we would like to thank all of the volunteers who have donated their computing time to climateprediction.net.

\section{AUTHOR CONTRIBUTIONS}

G.D.C., K.K., E.R., S.S., D.C., and B.v.d.H. designed the analysis. S.S. and D.W. provided the model simulations. G.D.C. performed the analysis and wrote the first draft of the paper. All authors contributed to the interpretation of the results and to the writing of the paper.

\section{FUNDING}

Open Access funding enabled and organized by Projekt DEAL. 


\section{COMPETING INTERESTS}

The authors declare no competing interests.

\section{ADDITIONAL INFORMATION}

Supplementary information The online version contains supplementary material available at https://doi.org/10.1038/s41612-021-00211-9.

Correspondence and requests for materials should be addressed to G.Di Capua.

Reprints and permission information is available at http://www.nature.com/ reprints

Publisher's note Springer Nature remains neutral with regard to jurisdictional claims in published maps and institutional affiliations.
Open Access This article is licensed under a Creative Commons Attribution 4.0 International License, which permits use, sharing, adaptation, distribution and reproduction in any medium or format, as long as you give appropriate credit to the original author(s) and the source, provide a link to the Creative Commons license, and indicate if changes were made. The images or other third party material in this article are included in the article's Creative Commons license, unless indicated otherwise in a credit line to the material. If material is not included in the article's Creative Commons license and your intended use is not permitted by statutory regulation or exceeds the permitted use, you will need to obtain permission directly from the copyright holder. To view a copy of this license, visit http://creativecommons. org/licenses/by/4.0/.

(c) The Author(s) 2021 